\title{
The middle and inner ears of the Palaeogene golden mole Namachloris: a comparison with extant species
}

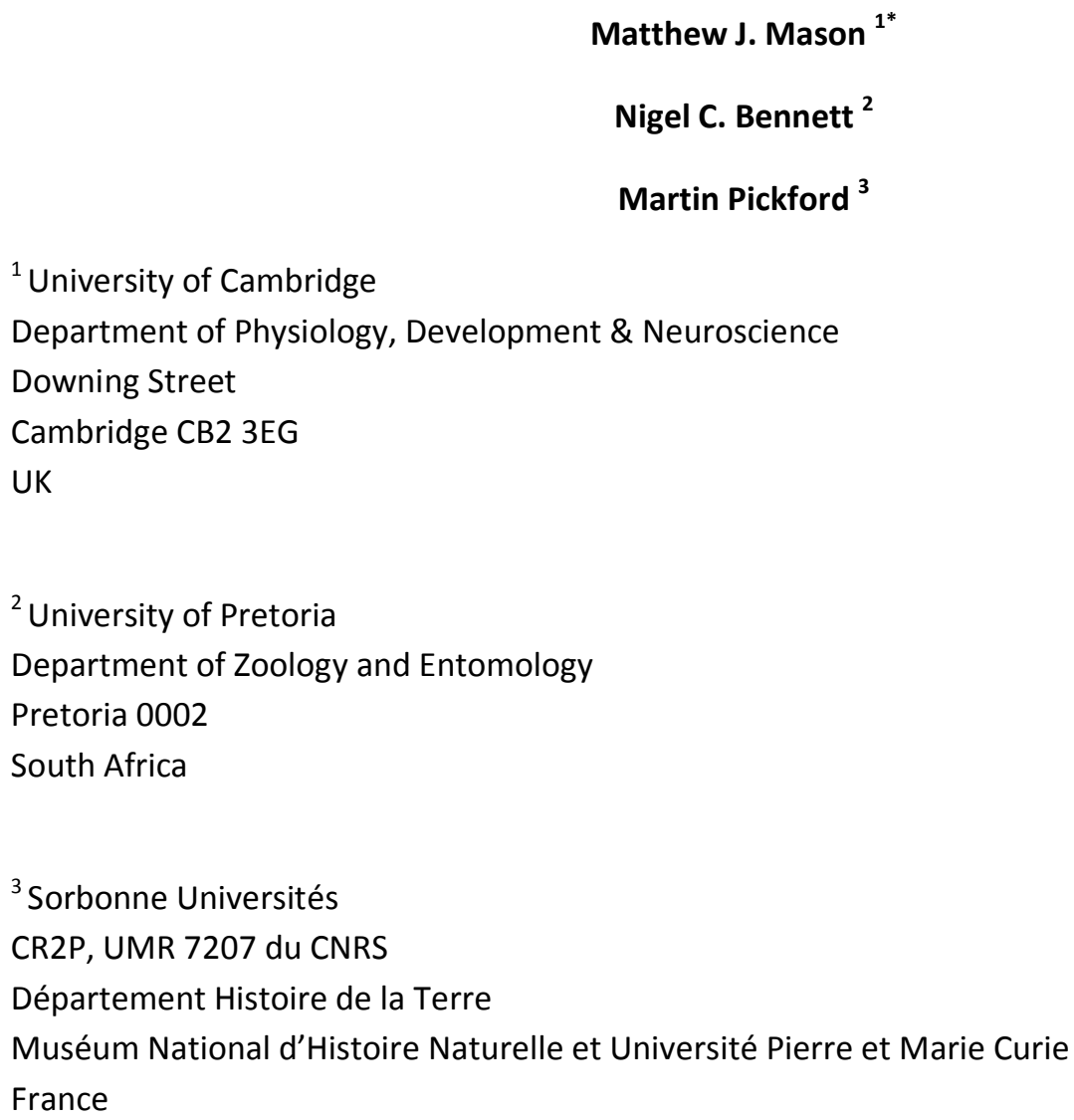

Keywords: Namachloris, middle ear, inner ear, Afrotheria, Chrysochloridae 


\section{Graphical abstract text}

The Palaeogene chrysochlorid Namachloris had small ossicles and a tensor tympani muscle. Its middle ear cavities did not intercommunicate. Like some other afrotherians, it had a secondary crus commune but no distinct canaliculus cochleae.

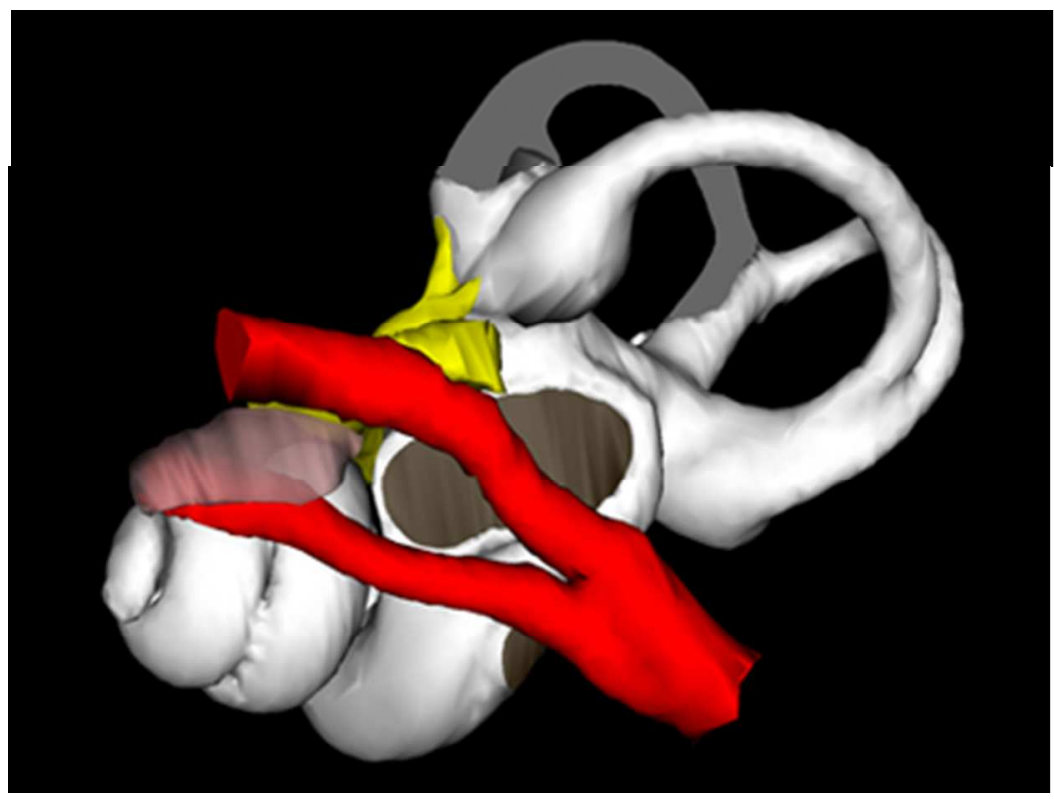

Graphical Abstract Image

$141 \times 105 \mathrm{~mm}(72 \times 72 \mathrm{DPI})$ 


\begin{abstract}
Many living species of golden moles (Chrysochloridae) have greatly enlarged middle ear ossicles, believed to be used in the detection of ground vibrations through inertial bone conduction. Other unusual features of chrysochlorids include internally-coupled middle ear cavities and the loss of the tensor tympani muscle. Our understanding of the evolutionary history of these characteristics has been limited by the paucity of fossil evidence. In this paper, we describe for the first time the exquisitely-preserved middle and inner ears of Namachloris arenatans from the Palaeogene of Namibia, visualised using computed tomography, as well as ossicles attributed to this species. We compare the auditory region of this fossil golden mole, which evidently did not possess a hypertrophied malleus, to those of three extant species with similarly-sized ear ossicles, Amblysomus hottentotus, Calcochloris obtusirostris and Huetia leucorhinus. The auditory region of Namachloris shares many common features with the living species, including a pneumatized, trabeculated basicranium and lateral skull wall, arteries and nerves of the middle ear contained in bony tubes, a highly coiled cochlea, a secondary crus commune and no identifiable canaliculus cochleae for the perilymphatic duct. However, Namachloris differs from extant golden moles in the apparent absence of a basicranial intercommunication between the right and left ears, the possession of a tensor tympani muscle and aspects of ossicular morphology. One Namachloris skull showed what may be pneumatization of some of the dorsal cranial bones, extending right around the brain. Although the ossicles are small in absolute terms, one of the Huetia leucorhinus specimens had a more prominent malleus head than the other. This potentially represents a previouslyunrecognised subspecific difference.
\end{abstract}




\section{Introduction}

Golden moles (Chrysochloridae) are a group of burrowing mammals endemic to Africa. They form part of the Afrotherian clade, within which they are united with tenrecs (Tenrecidae) within the Afrosoricida (e.g. Beck, Bininda-Emonds, Cardillo, Liu and Purvis, 2006; Kuntner, May-Collado and Agnarsson, 2011; Seiffert, 2007; Stanhope et al., 1998). Phylogenies of golden moles based on combined molecular and morphological data (Asher et al., 2010; Fig. 1) did not establish with any certainty the position of the root of the chrysochlorid tree, but the clade was broadly divided into amblysomines (Amblysomus, Neamblysomus and Carpitalpa species) and chrysochlorines, a group including all the remaining extant genera with the exception of Chlorotalpa, which is placed somewhere in-between. The taxon Huetia was elevated to a genus, containing the single species leucorhinus: this golden mole had formerly been classified within several other genera. We shall use the species nomenclature of Asher et al. (2010) throughout the present paper.

One of the most notable features of golden moles is the presence in many species of massively hypertrophied mallei (Forster Cooper, 1928; Mason, 2001; 2003b; 2007; von Mayer, O'Brien and Sarmiento, 1995). This is regarded as an adaptation to augment the detection of ground vibrations through ossicular inertial bone conduction (Lombard and Hetherington, 1993; Mason, 2003a; Willi, Bronner and Narins, 2006). The relatively small ossicles found in genera such as Amblysomus have been taken to be plesiomorphic for living chrysochlorids (Mason, 2003b; 2004; von Mayer et al., 1995). Such a conclusion would be reinforced if Calcochloris obtusirostris, a species with small ossicles, is placed at the base of a monophyletic Chrysochlorinae, as some of the maximum parsimony phylogenies reconstructed by Asher et al. (2010) suggested (see Fig. 1). However, Asher et al. (2010) noted that the golden mole taxa most frequently reconstructed as basal in their Bayesian analyses had "slightly enlarged" (Huetia), elongated (Chrysochloris, Cryptochloris) or enlarged and globular (Eremitalpa) mallei. Asher et al. raised the possibility that small ossicles may, 


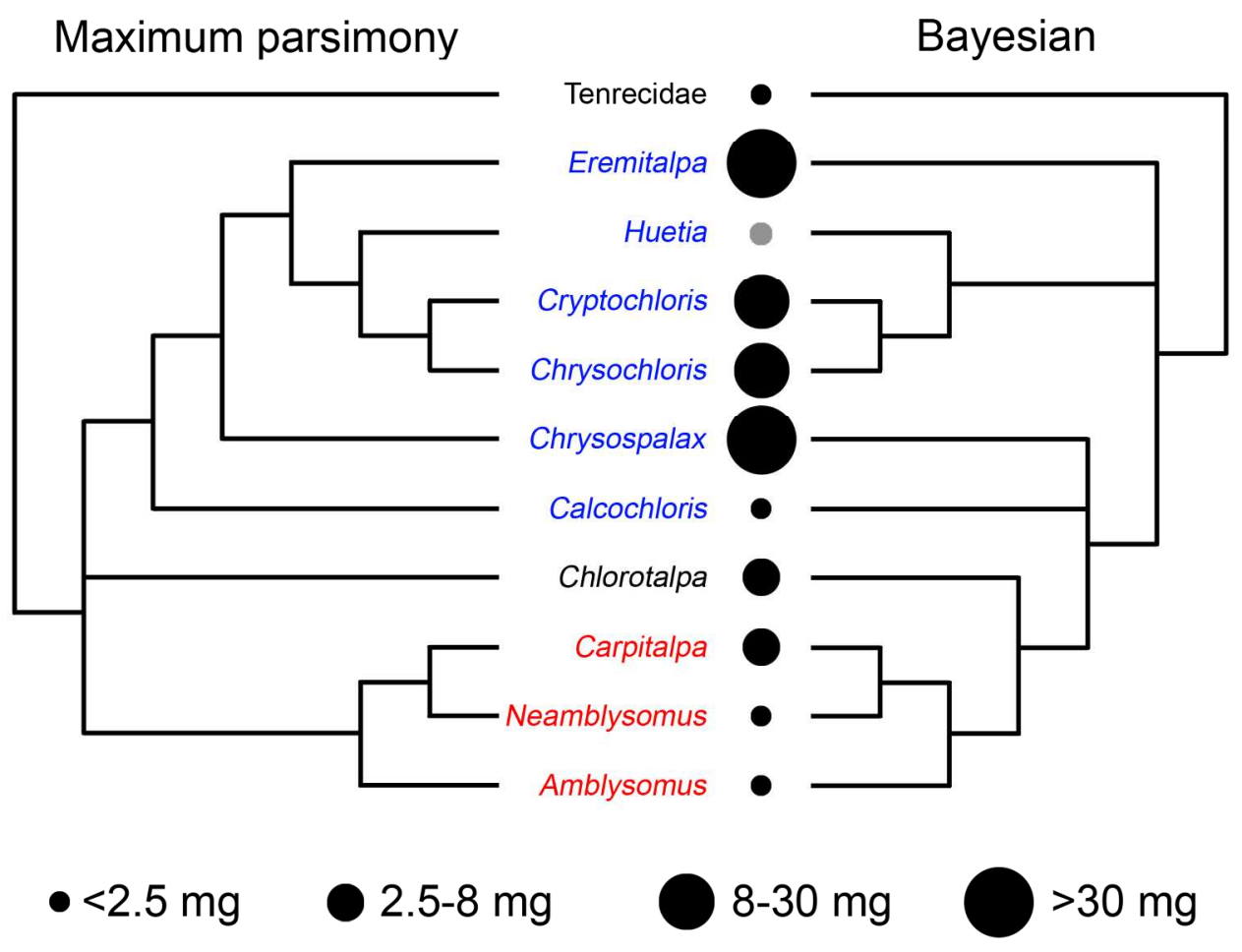

Fig. 1. Optimal phylogenetic trees of extant golden moles, after Asher et al. (2010). The left tree was produced using maximum parsimony (MP) methods, the right tree using Bayesian methods. Branch lengths are arbitrary. Genera grouped as 'chrysochlorines' are represented in blue: this group is only monophyletic according to the MP tree. Genera grouped as 'amblysomines' are represented in red. The circles indicate approximate malleus mass in each group (data from Mason, 1999; 2003b; Mason et al., 2006). The malleus mass of Huetia has not been directly measured, but is estimated in the present study to be well under $1 \mathrm{mg}$. 
in fact, be derived among extant golden moles, a suggestion later echoed by Crumpton et al. (2015), based on similar phylogenetic arguments.

Another strikingly unusual feature of nearly all golden moles is the fact that right and left middle ear cavities are mutually interconnected, via a pneumatized basisphenoid bone (reviewed by Mason, 2016a). Some talpid moles (Talpidae), a laurasiatherian group placed in the Eulipotyphla by e.g. Beck et al. (2006), possess a similar communication between their ears. This may represent an adaptation to permit pressure-difference sound localisation at low frequencies (Coles, Gower, Boyd and Lewis, 1982). Interestingly, ossicular hypertrophy has also evolved within the talpids (Mason, 2006;

Stroganov, 1945), and golden moles and talpid moles are among the few groups of mammals in which the tensor tympani muscle is lost (Mason, 2013).

The fossil record of the Chrysochloridae is fairly scanty, and has until now shed little light on the evolution of these unusual auditory characteristics. The Early Miocene fossil Prochrysochloris found in Kenya evidently had a pneumatized, trabeculated basicranium, as found in extant golden moles (Butler, 1984; Butler and Hopwood, 1957). A mandibular fragment from this species was also found in basal Miocene deposits in Namibia (Mein and Pickford, 2003). Prochrysochloris did not possess an externally-visible, swollen epitympanic region for accommodating a hypertrophied malleus head (Asher, 2010), and neither did Proamblysomus antiquus, Chlorotalpa spelea (Broom, 1941) nor "Chrysotricha" hamiltoni (De Graaff, 1958), three fossil species from the Plio-Pleistocene of South Africa. A species of Chrysochloris which did have a hypertrophied malleus was described from the early Pliocene of Langebaanweg, South Africa (Asher and Avery, 2010). No evidence from the ear region is known for the purported early Oligocene chrysochloroid from the Fayum, Egypt, Eochrysochloris tribosphenus (Seiffert, Simons, Ryan, Bown and Attia, 2007). On the basis of its plesiomorphic dental characteristics, it has been argued that Eochrysochloris may in fact represent a member of the tenrec clade rather than a golden mole (Pickford, 2015d). 
The freshwater limestone deposits at Eocliff, in the Sperrgebiet (Forbidden Territory) of Namibia, have recently yielded abundant material of a species described as Namachloris arenatans (Pickford, 2015d). This animal is represented by dental, cranial and postcranial skeletal elements which demonstrate morphological features typical of golden moles. A few isolated ear ossicles found in the same deposits were interpreted as belonging to this species too (Pickford, 2015d). The Black Crow deposits, also in the Sperrgebiet, have yielded a lower molar belonging to Diamantochloris inconcessus, another member of the golden mole clade (Pickford, 2015c). More teeth belonging to this animal have subsequently been found, but are not yet described.

\section{Dating the Sperrgebiet specimens}

Pickford et al. (2008) described four highly fossiliferous deposits in the Sperrgebiet: Silica North, Silica South, Black Crow and Steffenkop. Based on a comparison of the diverse collection of mammalian specimens found at the first three localities with those described from other African sites, Pickford et al. cautiously concluded that these Sperrgebiet deposits are Lutetian in age. This conclusion was backed up by stratigraphic and radioisotope evidence (Pickford, Sawada, Hyodo and Senut, 2013). Currently dated from 47.8 to $41.0 \mathrm{Ma}$ (Ogg, Ogg and Gradstein, 2016), the Lutetian falls in the early middle Eocene. Further mammalian fossil deposits were later found within the carbonate outcrops at Eoridge and nearby Eocliff. The presence of the anthracothere Bothriogenys (Pickford, 2015a) and the large titanohyracid Rupestrohyrax (Pickford, 2015f) at Eoridge prompted a reconsideration of the deposits of the area. It was concluded that there are two sets of fossiliferous limestones in the Sperrgebiet, rather than a single set as previously assumed. Fossiliferous Priabonian (late Eocene) marine deposits in the Bogenfels area contain reworked clasts of silicified limestone resembling those of Eocliff, on which basis it was concluded that the Eocliff deposits must be older than Priabonian (Pickford, 2015b). Pickford et al. (2014) and Pickford (2015b) continued to consider the Black Crow site Lutetian, but the Silica sites, Eocliff and Eoridge were correlated to the 
Bartonian (late middle Eocene, currently dated 41.0 to 38.0 Ma: Ogg et al., 2016). Namachloris, found at Eocliff, was estimated to be late Bartonian in age (Pickford, 2015d).

The dating of these Sperrgebiet sites remains controversial, however. Coster et al. (2012) agreed that some of the specimens described by Pickford et al. (2008) may be mid-Eocene, but suggested that the hyracoid Namahyrax and certain rodents are younger than this. Marivaux et al. $(2014 ; 2012)$ noted similarities between some of the rodents found in the Silica localities, as described by Pickford et al. (2008), and Miocene species found elsewhere. They therefore proposed a Miocene age for those particular deposits. Sallam \& Seiffert (2016) argued that the Silica deposits and those of Eocliff and Eoridge too are likely to be late Oligocene. They based this on the observations that no anthracotheres of Bartonian age have ever been found elsewhere in Africa, including in the earliest Priabonian localities in the Fayum, Egypt, and that the Eocliff tenrecoids (Pickford, 2015e) appear to be morphologically intermediate between late Eocene/Oligocene and Miocene species.

Subsequent fossil finds have shown that the initial identifications of the poorly-represented rodents Bathyergoides sp. indet. and Apodecter cf. stromeri from Silica North (Pickford et al., 2008) require revision (P. Mein, pers. comm.). The other rodents from the Silica sites (Silicamys, Prepomonomys and Protophiomys) are now better represented by the Eocliff discovery, and support a pre-Miocene age for the assemblage.

\section{This study}

Although the true age of the Palaeogene Eocliff deposits which yielded Namachloris specimens remains in dispute, Namachloris is unquestionably one of the oldest-known members of the golden mole clade. Examining these Eocliff fossils would allow us better to understand the evolutionary history of the highly unusual auditory apparatus of these animals. In the present study, we used micro-computed tomography to visualise and describe for the first time the middle and inner ear 
region of Namachloris, together with some of the ossicles attributed to this animal. For comparative purposes, we also examined the ear regions of Amblysomus hottentotus, Calcochloris obtusirostris and Huetia leucorhinus, extant species known to have relatively small ossicles (Mason, 2003b; Mason, Lucas, Wise, Stein and Duer, 2006; Simonetta, 1968; von Mayer et al., 1995). Little information is available about the ear of Calcochloris and less still about Huetia, but these animals are of particular interest because they lack grossly hypertrophied ossicles, and hence might possess plesiomorphic middle ear characteristics.

\section{Material and methods}

\section{Specimens}

A full list of specimens attributed to Namachloris arenatans, curated at the Geological Survey Museum, Windhoek, was published by Pickford (2015d). Skull and ossicular material relevant to this paper was found at three separate bone concentrations, EC 7, EC 9 and EC 10, all within the main limestone massif at Eocliff (Table 1). These bone concentrations are interpreted as the remains of regurgitation pellets that had accumulated beneath owl roosts in trees growing close to a hardwater spring. Fossils had been prepared by dissolving away the limestone matrix in a $7 \%$ formic acid solution, buffered with calcium triphosphate. All fossils were then consolidated in a dilute solution of glyptol in acetone; the more delicate specimens were additionally strengthened with cyanoacrylate, visible as grey material in some of the tomograms.

The most useful specimen of Namachloris arenatans proved to be the holotype skull GSN Na 1, which retained both right and left auditory regions. Unless otherwise specified, "Namachloris" in the text below refers to this specimen. The GSN Na 2 skull, from the same location, lacked occiput and much of the basicranium. The external features of these two fossil skulls have been previously described, together with postcranial remains attributed to this species (Pickford, 2015d). 


\section{Table 1}

Fossil material examined as part of the present study, all from Eocliff, in the Sperrgebiet, Namibia.

See Pickford (2015d) for details of further Namachloris material found in the same locations. GSN Na

= Geological Survey of Namibia Namachloris specimen, housed in the Geological Survey Museum,

Windhoek, Namibia.

\begin{tabular}{|c|c|c|c|}
\hline $\begin{array}{l}\text { Bone } \\
\text { concentration }\end{array}$ & Location & Catalogue no. & Namachloris material examined \\
\hline \multirow[t]{5}{*}{ EC 7} & \multirow{5}{*}{$\begin{array}{l}27^{\circ} 20^{\prime} 57.5^{\prime \prime S}, \\
15^{\circ} 35^{\prime} 44.1^{\prime \prime} \mathrm{E}: \\
\text { altitude } 384 \mathrm{~m}\end{array}$} & GSN Na 1 & Skull with both mandibles (holotype) \\
\hline & & GSN Na 2 & Skull with right mandible \\
\hline & & GSN Na 120a-e & Five incudes \\
\hline & & GSN Na 121a-b & Two incudes \\
\hline & & GSN Na 122a, b & One malleus, one incus \\
\hline EC 9 & $\begin{array}{l}27^{\circ} 20^{\prime} 57.6^{\prime \prime S}, \\
15^{\circ} 35^{\prime} 43.5^{\prime \prime} \mathrm{E}: \\
\text { altitude } 366 \mathrm{~m}\end{array}$ & GSN Na 101a, b & One malleus, one incus \\
\hline EC 10 & $\begin{array}{l}27^{\circ} 21^{\prime} 01.1^{\prime \prime S}, \\
15^{\circ} 35^{\prime} 43.2^{\prime \prime E}: \\
\text { altitude } 392 \mathrm{~m}\end{array}$ & GSN Na 7a, b & Two mallei \\
\hline
\end{tabular}


Additionally, we examined a large number of isolated, fossilized ear ossicles from the same region. Most were from rodents, but among these were nine incudes and four mallei (Table 1) which, by comparison with the two mallei found with GSN Na 1, were taken to be from Namachloris (see Results).

Five prepared skulls of Calcochloris obtusirostris were examined in The Natural History Museum, London (BMNH 6.11.8.27, 6.11.2.28, 84.8.30.1, 1906.11.8.25 and 1906.11.8.26), of which the last two were obtained on loan. These two borrowed specimens had both been collected in Inhambane, Mozambique. Five prepared skulls of the species here referred to as Huetia leucorhinus were also examined in The Natural History Museum (BMNH 9.12.12.3, 26.7.6.155, 26.11.1.60, 1926.7.6.154, 1963.1012), of which the last two were obtained on loan. Specimen BMNH 1926.7.6.154 had been collected in Luluabourg in what is now the Democratic Republic of the Congo, while BMNH 1963.1012 had been collected in Canzar, Angola. All four borrowed specimens were CT-scanned. We also obtained two heads of Amblysomus hottentotus, which had been collected in San Lameer, Natal, South Africa, under permit from Ezemvelo Nature Conservation, KwaZulu-Natal. These specimens had been fixed in 70\% ethanol for 2-3 years. After CT-scanning, the Amblysomus heads were dissected under light microscopy and further scans were made.

\section{CT scanning and reconstruction}

Specimens of fossil and extant species were scanned in the Nikon XT H 225 CT-scanner at the Cambridge Biotomography Centre. 1080 projections were taken of each specimen using settings of 1000 ms exposure time, $125-135 \mathrm{kV}$ and $110-125 \mu \mathrm{A}$. Two frames were averaged per projection. $\mathrm{CT}$ Agent XT 3.1.9 and CT Pro 3D XT 3.1.9 (Nikon Metrology, 2004-13) were used in creating the tomograms. Cubic voxel side-lengths were 6.2-15.3 $\mu \mathrm{m}$ (Table 2). 
Table 2

List of CT scans made as part of this study.

\begin{tabular}{|c|c|c|c|}
\hline Scan & Specimen & $\begin{array}{l}\text { Museum provenance } \\
\text { of specimen }\end{array}$ & $\begin{array}{c}\text { Voxel side length, } \\
\mu \mathrm{m}\end{array}$ \\
\hline 1 & $\begin{array}{l}\text { Namachloris GSN Na 1, whole (damaged) } \\
\text { skull }\end{array}$ & $\begin{array}{l}\text { Geological Survey } \\
\text { Museum, Windhoek }\end{array}$ & 12.6 \\
\hline 2 & Namachloris GSN Na 1, posterior skull & $\begin{array}{l}\text { Geological Survey } \\
\text { Museum, Windhoek }\end{array}$ & 9.4 \\
\hline 3 & $\begin{array}{l}\text { Namachloris GSN Na 2, whole (damaged) } \\
\text { skull }\end{array}$ & $\begin{array}{l}\text { Geological Survey } \\
\text { Museum, Windhoek }\end{array}$ & 14.1 \\
\hline 4 & $\begin{array}{l}\text { Four fossil mallei (GSN Na 7a, b, 101a, } \\
\text { 122a) }\end{array}$ & $\begin{array}{c}\text { Geological Survey } \\
\text { Museum, Windhoek }\end{array}$ & 6.5 \\
\hline 5 & $\begin{array}{l}\text { Three fossil incudes (GSN Na 101b, 121a, } \\
\text { b) }\end{array}$ & $\begin{array}{l}\text { Geological Survey } \\
\text { Museum, Windhoek }\end{array}$ & 7.6 \\
\hline 6 & Four fossil incudes (GSN Na 120a-d) & $\begin{array}{l}\text { Geological Survey } \\
\text { Museum, Windhoek }\end{array}$ & 7.6 \\
\hline 7 & $\begin{array}{l}\text { Amblysomus hottentotus NB1, whole } \\
\text { head }\end{array}$ & Not accessioned & 15.3 \\
\hline 8 & $\begin{array}{l}\text { Amblysomus hottentotus NB1, posterior } \\
\text { head }\end{array}$ & Not accessioned & 10.9 \\
\hline 9 & $\begin{array}{l}\text { Amblysomus hottentotus NB1, left ear } \\
\text { region, with Amblysomus hottentotus } \\
\text { NB2 left malleus and incus }\end{array}$ & Not accessioned & 6.2 \\
\hline 10 & $\begin{array}{l}\text { Amblysomus hottentotus NB2, whole } \\
\text { head }\end{array}$ & Not accessioned & 15.2 \\
\hline 11 & $\begin{array}{l}\text { Amblysomus hottentotus NB2, posterior } \\
\text { head }\end{array}$ & Not accessioned & 10.9 \\
\hline 12 & $\begin{array}{l}\text { Calcochloris obtusirostris } \\
\text { BMNH 6.11.8.25, whole skull }\end{array}$ & $\begin{array}{l}\text { Natural History } \\
\text { Museum, London }\end{array}$ & 11.5 \\
\hline 13 & $\begin{array}{l}\text { Calcochloris obtusirostris } \\
\text { BMNH 6.11.8.25, posterior skull }\end{array}$ & $\begin{array}{l}\text { Natural History } \\
\text { Museum, London }\end{array}$ & 8.7 \\
\hline 14 & $\begin{array}{l}\text { Calcochloris obtusirostris } \\
\text { BMNH 6.11.8.26, whole skull }\end{array}$ & $\begin{array}{l}\text { Natural History } \\
\text { Museum, London }\end{array}$ & 12.1 \\
\hline 15 & $\begin{array}{l}\text { Calcochloris obtusirostris } \\
\text { BMNH 6.11.8.26, posterior skull }\end{array}$ & Natural History & 8.7 \\
\hline
\end{tabular}




\begin{tabular}{|c|l|c|c|}
\hline 16 & $\begin{array}{l}\text { Muetia leucorhinus BMNH 63.1012, } \\
\text { whole skull }\end{array}$ & $\begin{array}{c}\text { Natural History } \\
\text { Museum, London }\end{array}$ & 11.8 \\
\hline 17 & $\begin{array}{l}\text { Huetia leucorhinus BMNH 63.1012, } \\
\text { posterior skull }\end{array}$ & $\begin{array}{c}\text { Natural History } \\
\text { Museum, London }\end{array}$ & 8.7 \\
\hline 18 & $\begin{array}{l}\text { Huetia leucorhinus BMNH 26.7.6.154, } \\
\text { whole skull }\end{array}$ & $\begin{array}{l}\text { Natural History } \\
\text { Museum, London }\end{array}$ & 8.7 \\
\hline 19 & $\begin{array}{l}\text { Huetia leucorhinus BMNH 26.7.6.154, } \\
\text { posterior skull }\end{array}$ & $\begin{array}{l}\text { Natural History } \\
\text { Museum, London }\end{array}$ & \\
\hline
\end{tabular}


Tiff stacks were converted to 8-bit jpeg files using Adobe Photoshop CS 8.0 (Adobe Systems Inc., 2003). 3D reconstructions were then made using WinSurf 4.0 (E. Neufeld, 2001) and MicroView 2.5.0 (Parallax Innovations Inc., 2017). WinSurf was particularly important in allowing the visualisation of hollow structures, such as the bony labyrinth and middle ear cavity. In order to create a WinSurf reconstruction, boundaries of a particular object were selected either manually or semiautomatically across a subset of tomogram slices. The outer wall of the middle ear cavity was modelled, ignoring the internal bony trabeculae.

Within the middle ears of golden moles, the facial nerve, stapedius muscle belly and major branches of the internal carotid artery are contained within bony tubes. The positions of these structures were estimated by reconstructing the inner boundaries of the tubes in WinSurf. Where tubes converged such that two structures shared a common canal, their relative positions could only be estimated. Smaller structures which share the same bony tubes, such as minor nerve branches, could not be traced.

There proved to be minor damage to the ear regions in the prepared skulls of Calcochloris and Huetia. In some ears, ossicles were displaced or broken, or small parts of the semicircular canals were missing. Fortunately, intact ossicles were found in at least one ear per species, and the overall morphology of the inner ear could be readily determined by comparison between specimens. Calculations of cochlear turns and cochlear duct lengths were made from the CT reconstructions following the method given by Mason et al. (2016).

Images of extant species, but not fossils, were laterally inverted where necessary, to facilitate comparison in the figures. 


\section{Ossicular measurements}

The auditory ossicles were dissected out of the two Amblysomus specimens and individually weighed on a Cahn C-31 microbalance. The lenticular apophysis broke from the incus and remained attached to the stapes in two of the four ears, but this very tiny process has little impact on the masses obtained. Ossicular masses could not be measured directly for Calcochloris and Huetia, because these valuable specimens could not be dissected, and the masses of fossil Namachloris ossicles would not equate to their masses in vivo. Ossicular masses in these species were instead estimated from their volumes, assuming the same ossicular densities as were calculated for Amblysomus (see Discussion).

Ossicular volumes measured in MicroView depend upon the choice of a particular greyscale threshold value, taken to be the bone/non-bone cutoff. If the threshold is increased, the amount of material taken to be 'bone' declines, and thus the calculated ossicular volume drops. Ossicular volumes obtained across a range of thresholds were compared, and for each scan the final reconstruction threshold was chosen as the value at which the decline in ossicular volume with increasing threshold became linear. These values closely coincided with the values at which the 3D reconstructions appeared to be most accurate, but were inevitably slightly different from the volumes calculated using the visual identification of boundaries in WinSurf. Volumes and hence densities of Amblysomus ossicles were therefore separately calculated using each program (Table 3). These density values were then used to estimate the masses of the other ossicles examined, from their measured volumes. Masses estimated using each of the two volume measurement methods were averaged.

In order to compare malleus masses among a wider range of chrysochlorids, we used data from an additional eight species collected as part of an earlier study (Mason et al., 2006). Maximum skull lengths had been recorded for those specimens with skulls intact enough to make that measurement, and only these were included in the present analysis. Mean maximum skull lengths 
Table 3

Mean densities of Amblysomus ossicles, calculated using masses measured directly (see Table 4) and volumes measured from CT reconstructions made either in WinSurf or MicroView. Right and left ossicles were considered for each of two animals, so $n=4$ in every case.

\begin{tabular}{|c|c|c|}
\hline Ossicle & $\begin{array}{c}\text { Density (using WinSurf } \\
\text { volume), } \mathrm{mg} \mathrm{mm}^{-3}\end{array}$ & $\begin{array}{c}\text { Density (using MicroView } \\
\text { volume), } \mathrm{mg} \mathrm{mm}^{-3}\end{array}$ \\
\hline Malleus & 2.06 & 1.89 \\
\hline Incus & 2.09 & 1.94 \\
\hline Stapes & 1.67 & 1.32 \\
\hline
\end{tabular}


were obtained for each species, and paired with mean malleus masses from the same specimens (one malleus per skull, the left selected if there was a choice). Eremitalpa granti granti and E. $g$. namibensis were considered separately, since they have mallei of different shapes and sizes (Mason et al., 2006). Because the ossicles in the two Huetia specimens examined in the present study also proved to differ (see Results), they too were considered separately.

Stapes footplate areas and the oval window area of Namachloris were measured as flat surfaces from scaled MicroView reconstructions, using ImageJ 1.48v (W.S. Rasband, National Institutes of Health, USA, 1997-2016). Maximum skull lengths, from the rostral tip of the nasal bones to the posterior occiput, were measured with callipers. In the case of Namachloris, a maximum skull length of $24.1 \mathrm{~mm}$ for GSN Na 1 was estimated by digitally combining CT reconstructions of this specimen (which includes most of the posterior skull) and GSN Na 2 (which includes the rostral nasal region).

No live animals were used in this study. All aspects of the research adhered to relevant legal requirements.

\section{Results}

\section{The middle ear cavities}

Amblysomus, Calcochloris and Huetia have small, but prominent, auditory bullae on their ventral basicrania (Fig. 2). The ectotympanic component of this, which is ventrolateral, is almost indistinguishably fused to the surrounding bones. It encloses the circular tympanic membrane, behind which is the tympanic cavity. This is an air-filled space free of bony trabeculae, within which are found the manubrium of the malleus, the long process of the incus and the stapes; the cochlear promontory forms part of its dorsomedial wall. The major arteries and the facial nerve pass through the tympanic cavity enclosed within bony tubes (see later). In Namachloris GSN Na 1, the 


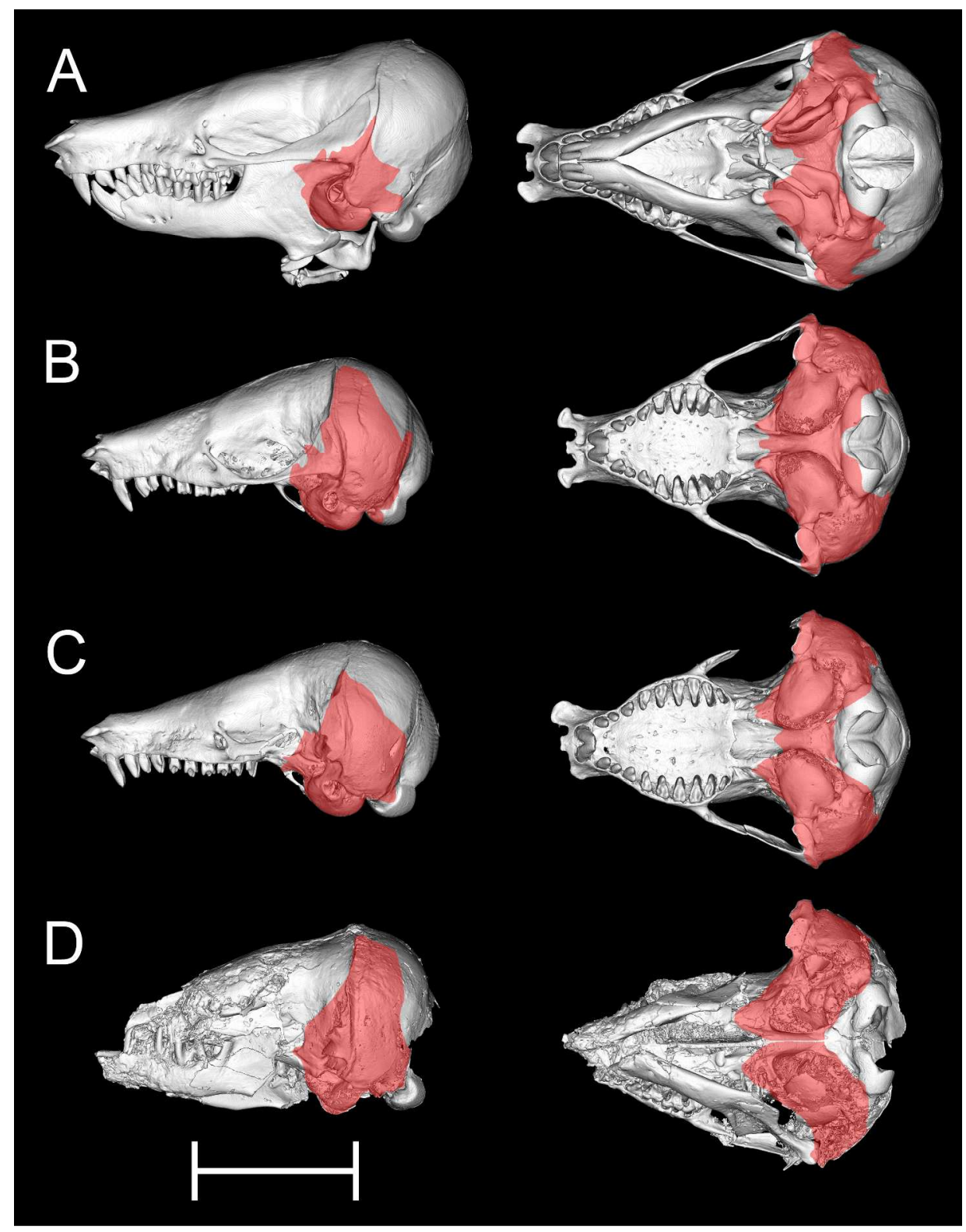

Fig. 2. CT reconstructions of the skulls of golden moles, in lateral (left) and ventral (right) views. The approximate extent of the middle ear cavities and the associated pneumatization is indicated by red shading. In the case of Namachloris, the boundaries of the middle ear cavities have been estimated where there has been damage to the fossil specimen. A: Amblysomus; B: Calcochloris; C: Huetia, Angola specimen; D: Namachloris GSN Na 1. Scale bar $10 \mathrm{~mm}$. 
ectotympanic on the left side is completely missing, revealing the contents of the tympanic cavity.

On the right side, the rostrolateral part of this bone remains. Unlike in the extant golden moles examined, there is a clear suture separating this part of the ectotympanic from the inflated, spongy bone which forms the rostromedial bulla.

Many of the bones surrounding the tympanic cavity in golden moles are invaded by extensions of the middle ear cavity, considerably enlarging the overall middle ear air space (Fig. 2). These pneumatized sinuses are partially filled with bony trabeculae, giving the bone a spongy appearance (Fig. 3). The lateral skull surrounding the cranial cavity, caudal to the base of the zygoma, is one such pneumatized region. This is a relatively small area in Amblysomus, but in the other species including Namachloris the pneumatized region extends dorsal to the zygoma, leaving much of the lateral skull wall pneumatized (Fig. 2-4). Extensive fusion of skull bones makes it impossible to be sure which bones are involved here, but the pneumatized region is likely to include alisphenoid and possibly squamosal components.

In all species, a sinus extends medially from the tympanic cavity, below the cochlear promontory, to penetrate and pneumatize what appears to be the basisphenoid bone. The basisphenoid pneumatization extends caudally from here; in Calcochloris only it penetrates the occipital condyles. It also extends medially, and in all specimens of Amblysomus, Calcochloris and Huetia a complete connection between right and left middle ear air spaces is formed within the inflated, trabeculated basisphenoid (Fig. 3A-C). In Namachloris, however, the right and left cavities remain separated by a very thin, irregularly-positioned, bony septum within the labyrinthine trabecular meshwork of the basisphenoid (Fig. 3D). Careful scrutiny of the tomogram sections failed to reveal any passage between right and left ears of this species, although the two pneumatized zones are extremely closely apposed.

The basicranium and occiput of Namachloris GSN Na 2 were missing, but what remains of the posterior skull is thick and spongy even dorsally (Fig. 5). The spongy area extends along the dorsal 


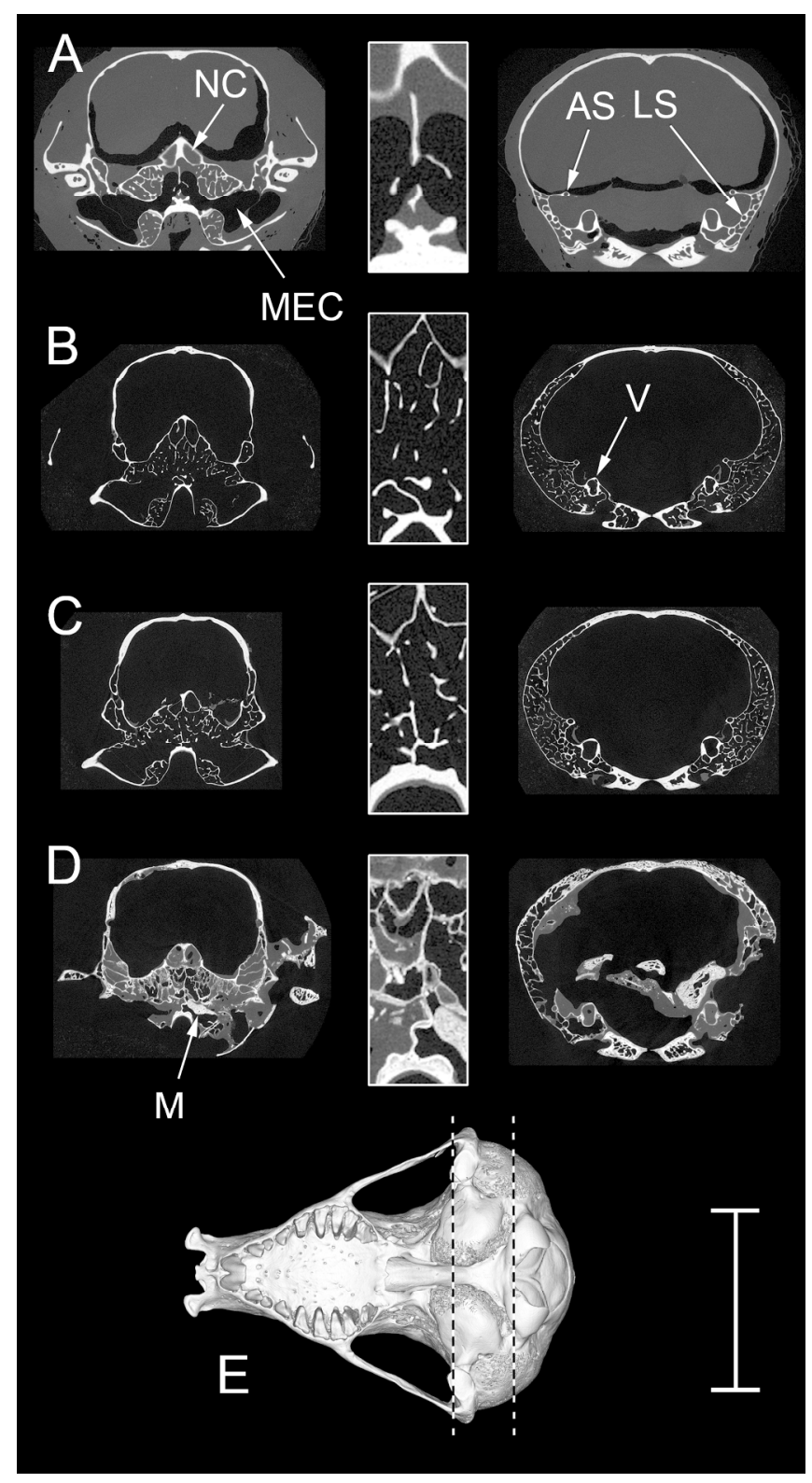

Fig. 3. CT transverse sections of the skulls of golden moles. The left column contains sections taken near the posterior limits of the nasal cavity (NC). In the central column are shown $\times 4$ enlargements of where the left and right middle ear cavities (MEC) meet in the midline, just beneath the nasal cavity. An

interconnection between left and right cavities is visible in all except Namachloris, in which the two sides are separated by a narrow septum. The right column contains sections taken at the anterior end of the foramen magnum, showing the variable extent of pneumatization of the lateral skull bones. The vestibule of the inner ear (V) together with the anterior and lateral semicircular canals (AS, LS) are visible. The zygomatic arches of Huetia are missing; the Namachloris specimen is more damaged and its cranial cavity contains some bony debris. A displaced right malleus $(\mathrm{M})$ is visible within the right middle ear cavity of this fossil specimen. A: Amblysomus; B: Calcochloris; C: Huetia, Congo specimen; D: Namachloris GSN Na 1; E: Ventral view of Calcochloris skull, used as an example to show the approximate positions of the two sets of sections. Scale bar represents $10 \mathrm{~mm}$ for left and right columns and for the skull reconstruction, but $2.5 \mathrm{~mm}$ for the central enlargements. 
aspect of the skull as far as the nasal region. By comparison with the extant species, this sponginess gives the appearance of resulting from pneumatization, as opposed to simply being marrow spaces within the bones. This raises the strikingly unusual possibility that right and left middle ear cavity extensions may meet over the top of the brain, a condition which has not been described in any extant golden mole. As in the basicranial region, right and left sides appear to remain separated by a very thin layer of bone, in which case there may not be any actual intercommunication of the supposed air cavities. In Namachloris GSN Na 1, the dorsal part of the calvarium is composed of more compact bone showing only very tiny openings, which were taken to be marrow spaces (Fig. 3D).

Among mammals in general, the heads of the malleus and incus usually lie within an epitympanic recess, dorsolateral to the tympanic cavity. In Amblysomus, Calcochloris and Huetia, the ossicular heads are accommodated within an open region of the middle ear cavity, but pneumatized sinuses extend from here into the surrounding bones such that there is no discrete epitympanic recess. There is damage to this region in Namachloris, on both sides, but the open area appears to be of similar volume to the equivalent spaces in the extant species examined. It does not extend into the orbital region, and is not large enough to accommodate significantly hypertrophied ossicles.

None of the auditory ossicles remain in position in Namachloris GSN Na 1. However, two right mallei, both very similar in morphology, were found associated with this fossil. One, with damaged manubrium, was found with other bony debris in the cranial cavity (Fig. 4D). The other was in the right middle ear cavity. Oriented approximately horizontally with respect to the skull, its head lay within the pneumatized basisphenoid, the manubrium projecting out laterally into the tympanic cavity, just below the right cochlea (Fig. 3D, 4D). If this were the original ossicle from that ear, it had clearly become displaced from its life position. 


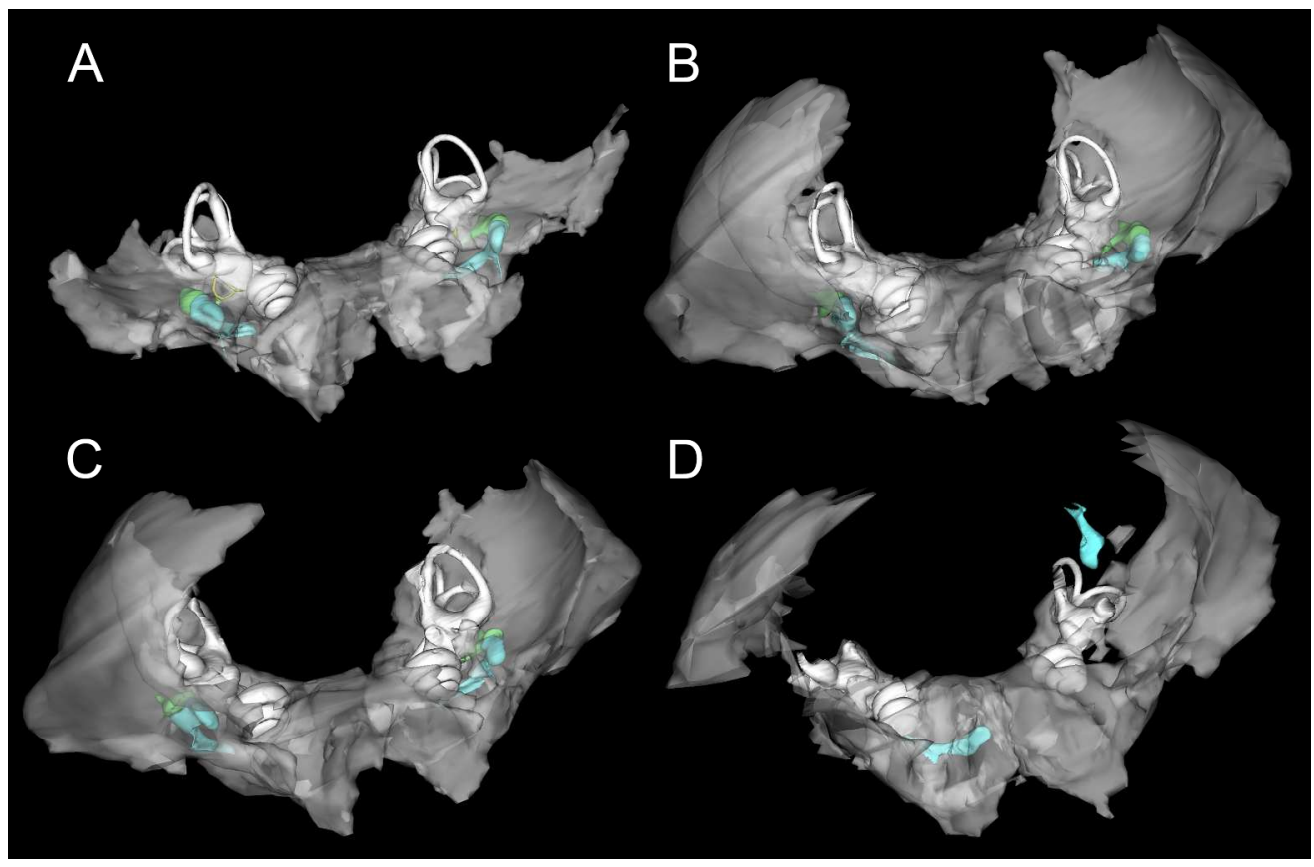

Fig. 4. WinSurf reconstructions of the middle ear cavities and associated structures of golden moles, each seen from an anterior, lateral and dorsal position. The boundaries of the middle ear cavities are indicated by translucent grey shading, but the bony trabeculae inside the cavities are not shown. The inner ears (bony labyrinths) are shown in white, mallei blue, incudes green and stapedes yellow. Owing to damage to the fossil specimen, parts of the middle ear cavities and inner ears of Namachloris are missing. The two displaced right mallei found associated with this fossil skull are shown, one in the right middle ear cavity, one in the cranial cavity. A: Amblysomus; B: Calcochloris; C: Huetia, Congo specimen; D: Namachloris GSN Na 1 . Not to scale. 


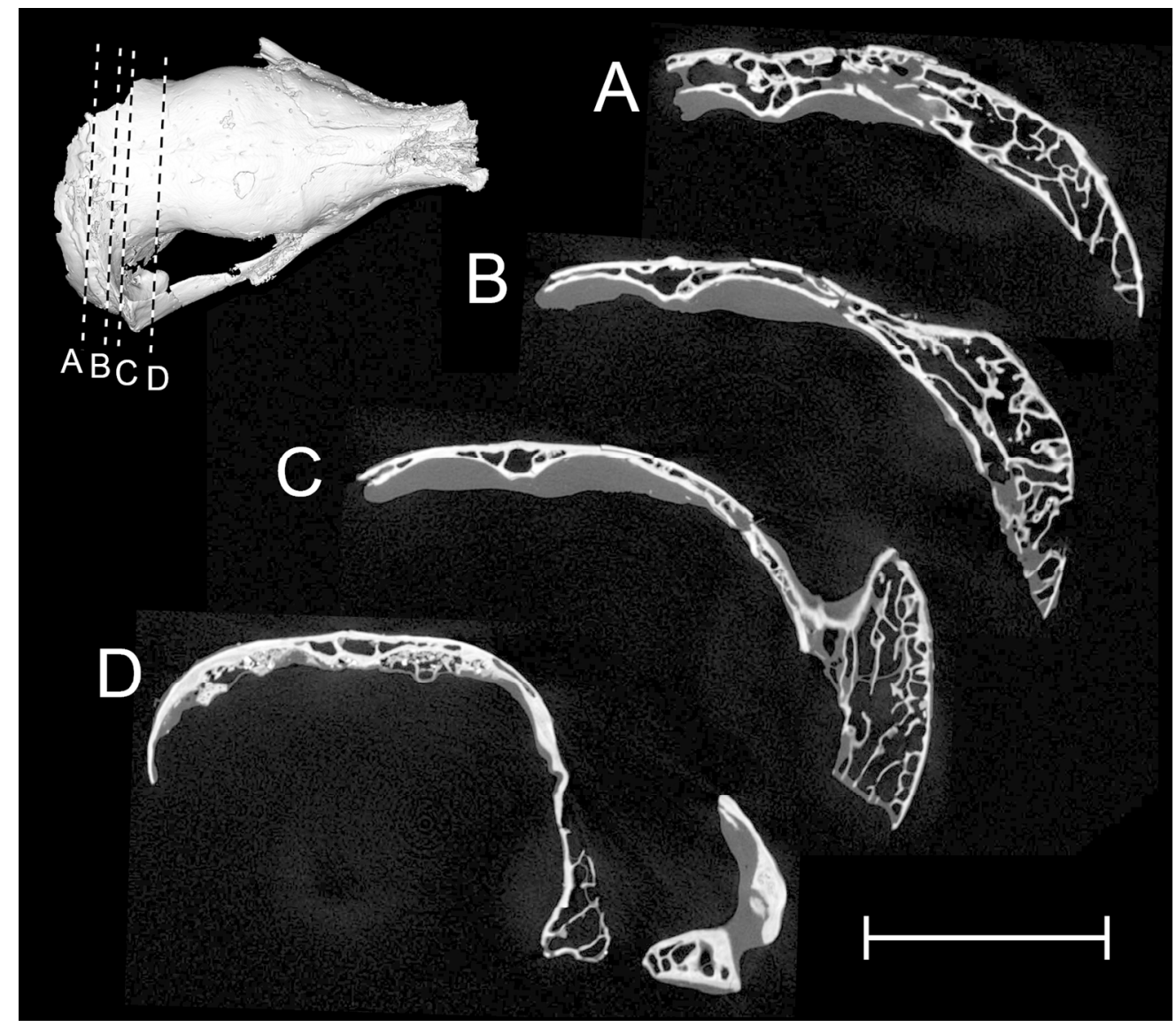

Fig. 5. Four CT sections through the skull of Namachloris fossil GSN Na 2, from posterior (A) to anterior (D). Their positions are indicated by dotted lines in the reconstruction shown top-left. The posterior calvarium and root of the zygoma are made of spongy bone which appears to be pneumatized. Unusually, the apparently pneumatized region reaches the very dorsal aspect of the skull in this specimen. Scale bar (for cross-sections only) $5 \mathrm{~mm}$. 


\section{Arteries, nerves and muscles}

The internal carotid artery enters the skull via the posterior carotid foramen. Travelling rostrodorsally, it soon divides into a ventromedial promontorial branch and a dorsolateral stapedial branch (Fig. 6). The promontorial branch passes over the lateral aspect of the cochlear promontory before entering the cranial cavity. The stapedial artery crosses the pelvis ovalis (the recess containing the stapes), passing through the stapedial foramen. Here, its bony canal was complete in Calcochloris and Huetia but incomplete in three out of four Amblysomus ears examined. Dorsal to the stapes, the tube for the stapedial artery merges with the tube for the facial nerve. The soft tissue structures could not be distinguished in the CT scans, but we interpret the stapedial artery as bending rostrally, whereupon it separates from the nerve and continues in its own tube. In the extant species, the tube for the stapedial artery then converges with that of the promontorial artery, beyond the pelvis ovalis (Fig. 6A-C). These two tubes, running adjacent to each other but remaining divided, open into the cranial cavity together, the stapedial branch immediately lateral to the promontorial branch. At this point, the stapedial artery divides into superior and inferior rami, which run in open canals. The superior ramus runs dorsolaterally, leaving the ear region. In Amblysomus and Calcochloris, the course of the inferior ramus is indicated by a canal on the dorsal surface of what is either the ectotympanic or petrosal bone, running rostrally towards the foramen ovale (the exit-point of nerve $V_{3}$ from the skull, not to be confused with the oval window into the inner ear). $A$ bridge of bone, representing a lateral extension of what is probably the alisphenoid, comes to cover this canal dorsally, narrowly dividing its exit from the skull from the foramen ovale just above.

In Huetia, the morphology differs in some respects. The stapedial artery opens into the cranial cavity closer to the foramen ovale, such that the inferior ramus has only a very short distance to run before exiting the skull. There is no bony bridge in this species and so the arterial branch leaves through the foramen ovale. In the Congo specimen only, on both left and right sides, the bony walls of the stapedial and promontorial arteries fuse where the arteries converge beyond the oval window, and 


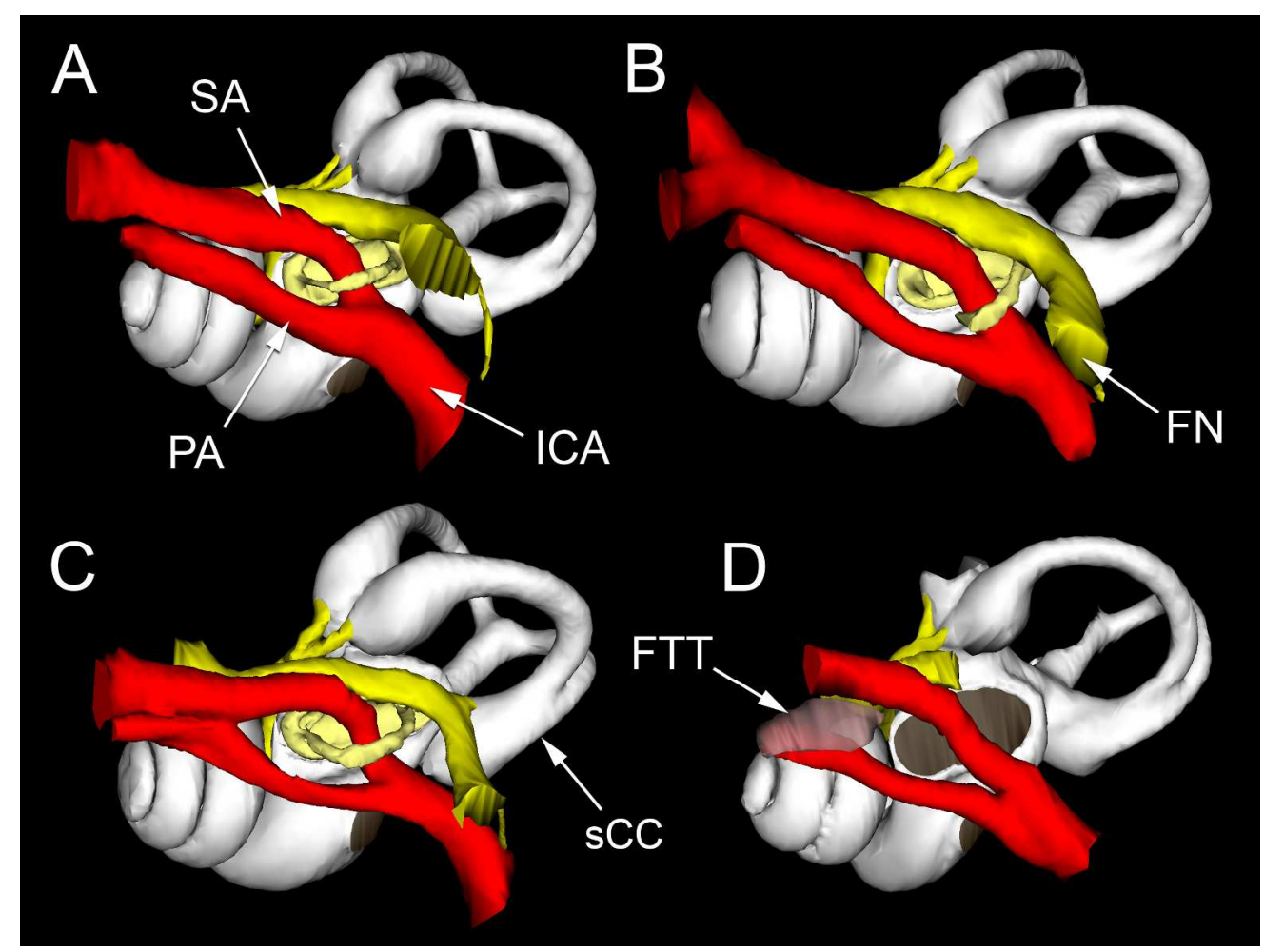

Fig. 6. WinSurf reconstructions of left ear structures of golden moles, seen from ventrolaterally. The bony labyrinths are shown in white, facial and vestibulocochlear nerves in yellow, arteries in red and stapedes in pale yellow. The fossa believed to contain the tensor tympani muscle in Namachloris is pink. Round and (in Namachloris only) oval windows have been shaded in brown. The positions of the nerves and arteries were inferred from their bony tubes. In Calcochloris, there was minor damage to the anterior semicircular canal and the stapes was broken. The anterior semicircular canal and stapes were missing in Namachloris, as was most of the tube containing its facial nerve. A: Amblysomus; B: Calcochloris; C: Huetia, Congo specimen; D: Namachloris GSN Na 1. FN: facial nerve; FTT: fossa for tensor tympani muscle; ICA: internal carotid artery; PA: promontorial artery; SA: stapedial artery; SCC = secondary crus commune. Not to scale. 
for a short stretch the two arteries are contained within a common tube (Fig. 6C). In the Angola specimen, on one side only, the tube for the stapedial artery gives off a small branch which proceeds dorsally to open into the cranial cavity before the main tube.

A bony tube surrounding the stapedial artery as it crosses the pelvis ovalis was preserved on the left side of Namachloris GSN Na 1, but what remains is fragmentary. It was not clear whether the tube would have been incomplete in life, as in some of the Amblysomus specimens, or whether this simply represents damage to the fossil specimen. The stapedial and promontorial arteries do not converge beyond the pelvis ovalis, instead remaining well separated and running parallel to each other (Fig. 6D). Between the two is a fossa for the tensor tympani muscle belly (see below). There is damage on both sides, but on the right side the tube for the stapedial artery can be seen to divide into tubes for the superior and inferior rami, while still within the middle ear cavity. The superior ramus travels dorsolaterally into the cranial cavity, while the inferior ramus continues rostrally, enclosed by the ectotympanic/petrosal below and pneumatized alisphenoid above. The foramen ovale takes the form of a short tube through the pneumatized alisphenoid further dorsally, remaining completely distinct from the exit point of the inferior ramus.

The facial nerve diverges from the vestibulocochlear nerve just posterior to the cochlea. Its bony tube runs for a very short distance rostrolaterally before converging with the tube for the stapedial artery (Fig. 6). We interpret the facial nerve as making its typically abrupt, 90-degree turn here before separating from the stapedial artery and passing through the middle ear within its own tube, in a posterior, lateral and ventral direction. The tube for the facial nerve combines with the tube for the stapedius muscle, separates from this, and the nerve finally leaves the skull at the stylomastoid foramen. The course of the facial nerve in Namachloris could not be reliably determined beyond the point where it separates from the stapedial artery, due to extensive damage to the middle ear region here on both sides. 
In both Huetia and Namachloris, the bony tube for the facial nerve opens into the cranial cavity, just rostrodorsal to the point where the nerve undergoes its 90-degree turn. This opening was taken to represent a very wide hiatus facialis, which normally conveys the greater petrosal nerve. In Calcochloris there is an extremely narrow tube in the corresponding position, while in Amblysomus no such opening was found. Presumably, the greater petrosal nerve in this animal enters the cranial cavity with the stapedial artery.

In all extant species, a very narrow bony tube was observed to pass between the posterior carotid foramen and the tube for the facial nerve. This was interpreted as carrying the internal carotid nerve, containing sympathetic fibres. A similar tube was identified on both sides in Namachloris, but in this fossil it originated from the tube for the promontorial artery, just after it separates from the stapedial artery, rather than from the carotid foramen.

The pterygoid canal, which typically carries a nerve branch and an artery, was identified in Amblysomus as a very narrow bony tube which penetrates into the trabeculated sphenoid region from the cranial cavity, just rostral to the cochlea. It travels rostroventrally before curving laterally, exiting the skull at the division between middle ear and nasal cavities. The pterygoid canal was not identifiable in Huetia and Calcochloris. In Namachloris, a bony tube was found which might represent the pterygoid canal. It was first visible just dorsal to the cochlear apex, running rostromedially into the sphenoid from the suture between sphenoid and petrosal. From here, the tube extends a short distance into the trabeculated sphenoid region and then disappears: evidently the structures within continue their journey through the middle ear cavity unenclosed.

A short bony tube containing the stapedius muscle belly was identified in all extant species. Arising in the posterior part of the middle ear cavity, this tube converges rostrally with the tube containing the facial nerve before diverging medially to open into the pelvis ovalis, just posterior to the stapes. The blind, posterior end of this tube was found on both right and left sides in Namachloris, but it was damaged rostrally. 
In both ears of the Namachloris specimen, an elongated fossa runs between the promontorial and stapedial arterial tubes (Fig. 6D). This open channel was interpreted as containing the belly of a tensor tympani muscle, which must have been relatively small. In the extant golden moles, the convergence of the stapedial and promontorial arteries eliminates this fossa: these animals show no signs of a tensor tympani.

\section{Ossicular morphology}

The malleus of Amblysomus has a rounded head; its articulation facet is curved in medial view and oval from a posterior view (Fig. 7B). Its anterior process is a relatively long, triangular lamina. The manubrium is broadly spatulate; as in Calcochloris and Huetia, it has no muscular process. The bony lateral process is not prominent, but it is augmented by cartilage. The malleus of Calcochloris (Fig. 7C) is very similar except that its anterior process is shorter, its articulation facet less curved and relatively narrower, and its manubrium a little narrower too. The mallei of Huetia depart more from this morphology and differ between the two specimens examined. The malleus head has a relatively small, rostrodorsal prominence in the Angola specimen (Fig. 7D), but it is larger and more bulbous in the Congo specimen, which also has a longer, narrower articulation facet which is more constricted in the middle (Fig. 7E). The Angola specimen has a prominent, bony lateral process to its manubrium; this is blunter in the Congo specimen in which it may be continued with cartilage. In both specimens, the inserting margins of the manubrium are relatively narrow and more triangular at the tip than in Amblysomus or Calcochloris. Tomograms showed that the anterior process in all extant species is a triangular bony lamina oriented more-or-less in the vertical plane. It tapers to become very narrow (narrowest in Huetia), whereupon it twists into the horizontal plane, expands slightly and is in bony union with the anterior wall of the tympanic cavity. 


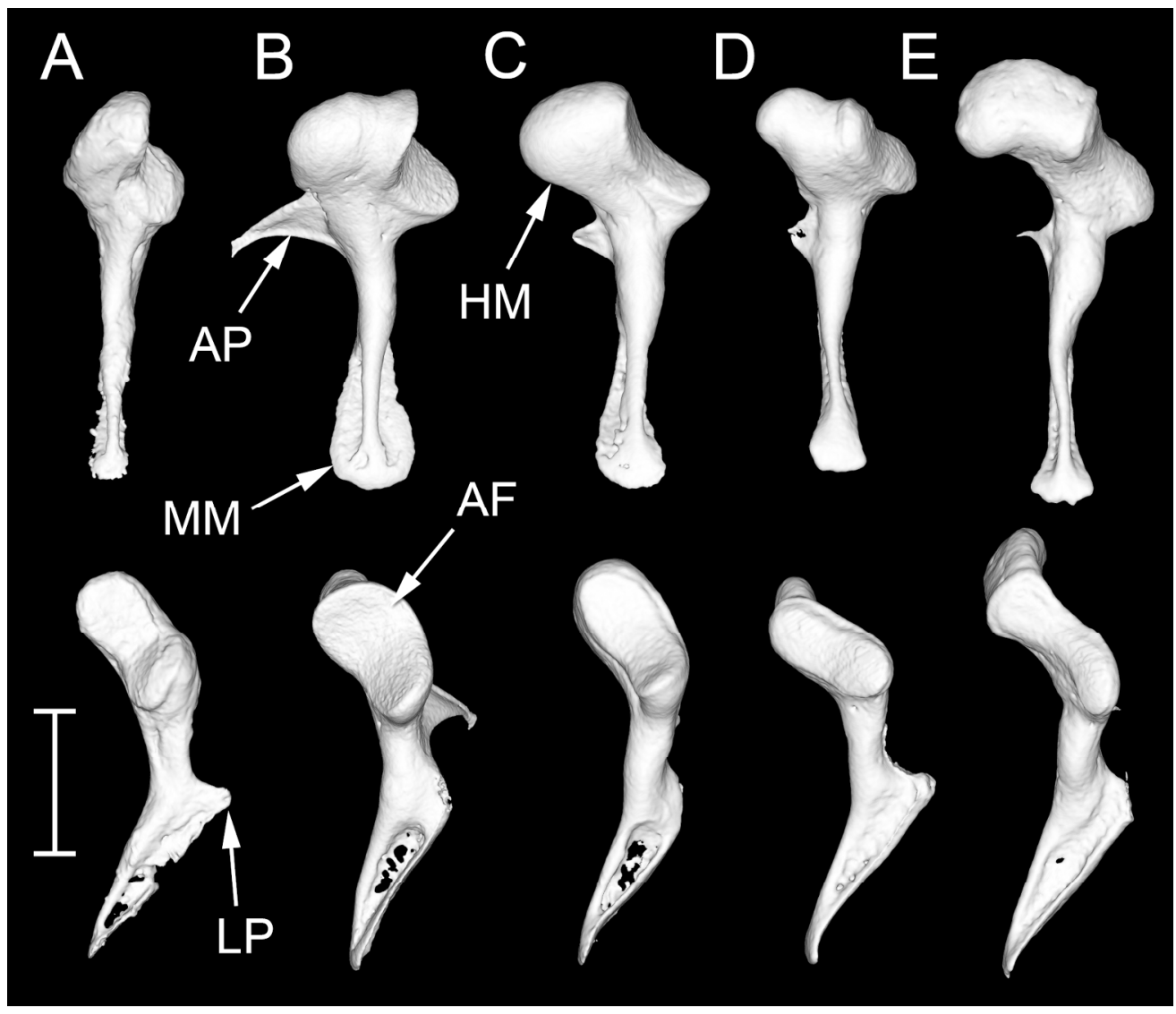

Fig. 7. CT reconstructions of the right mallei of golden moles, in approximately medial (top) and posterior (bottom) views. A: Damaged fossil malleus found in the right tympanic cavity of Namachloris GSN Na 1; B: Amblysomus; C: Calcochloris; D: Huetia, Angola specimen; E: Huetia, Congo specimen. AF: articulation facet; AP: anterior process; HM: head of malleus; LP: lateral process; MM: manubrium of malleus. Scale bar $1 \mathrm{~mm}$. 


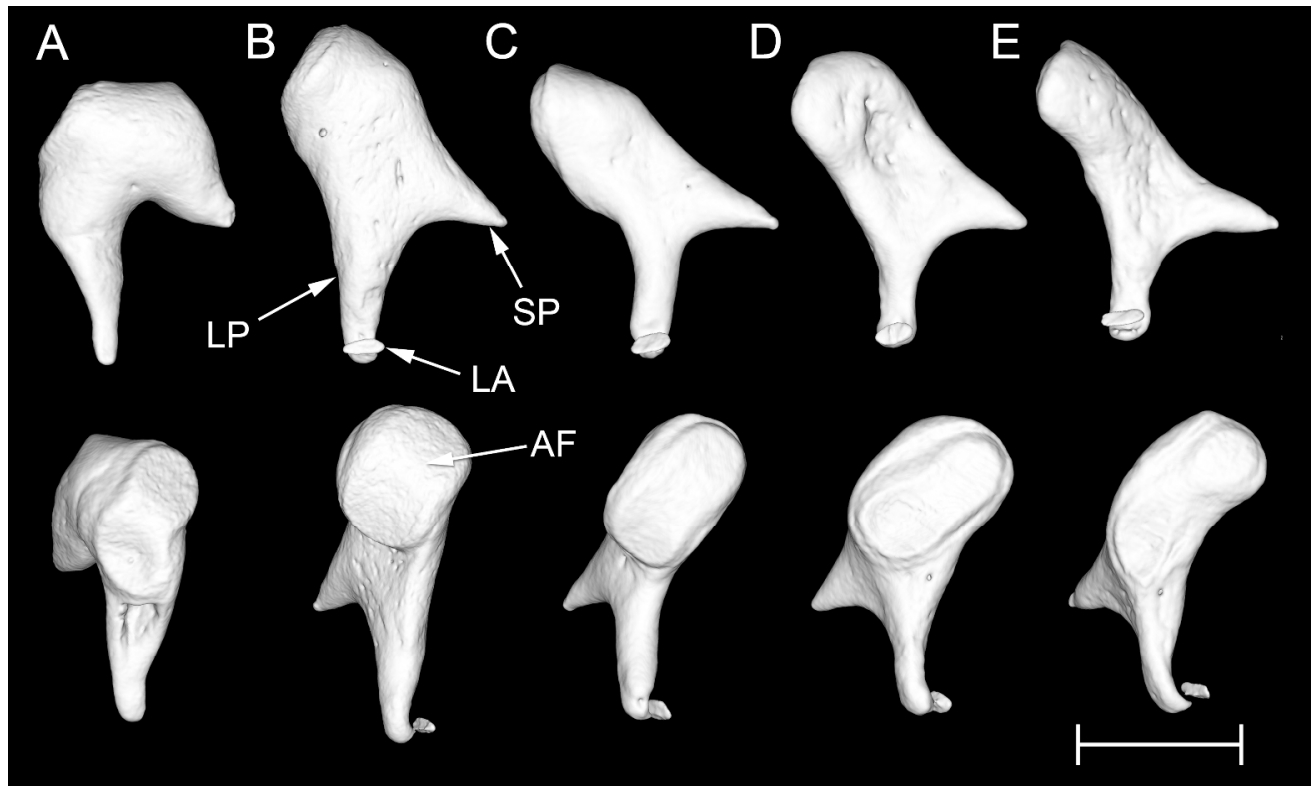

Fig. 8. CT reconstructions of the right incudes of golden moles, in approximately medial (top) and anterolateral (bottom) views. A: Fossil incus GSN Na 121a, attributed to Namachloris, lacking a lenticular apophysis; B: Amblysomus; C: Calcochloris; D: Huetia, Angola specimen; E: Huetia, Congo specimen. AF: articulation facet; LA: lenticular apophysis; LP: Iong process; SP: short process. Scale bar $1 \mathrm{~mm}$.

$1139 \times 681 \mathrm{~mm}(72 \times 72 \mathrm{DPI})$ 
The incudes of Amblysomus and Calcochloris (Fig. 8B, C) are similar. Each features a laterally flattened and rather rectangular body, supporting a conical short process and a broad articulation facet, this facet being more rounded in Amblysomus. The long process is inflected inwards at its tip, to support a small, oval lenticular apophysis. The incus of the Angolan Huetia (Fig. 8D) was similar. In the Congo specimen (Fig. 8E), the body of the incus was slimmer and the elongated articulation facet was more constricted centrally, tending further towards a 'figure-of-eight' conformation. The short process of one incus had a broader base than its contralateral counterpart, making the long process appear unusually short (Fig. 9E). The tip of the short process of the incus was contained within a shallow fossa in the posterior wall of the tympanic cavity in all extant species. There was no bony fusion visible, so this articulation is presumably ligamentous.

The stapedes of all of the extant species featured broad, robust footplates with well-developed labra (Fig. 10A-E). Their anterior ends tended to be blunter than the posterior ends. The centre of each footplate was concave on the tympanic side. The crura flare out to meet the footplate's labrum in Amblysomus and Calcochloris, but in Huetia, unusually, the posterior crura are joined to the footplate by means of two or three thin, bony struts. Further from the footplate, the crura become more slender and curve inwards to unite and form a small head. The posterior crus usually has a slightly thickened region near the head, marking the insertion point of the stapedius tendon. Stapedial morphology was quite variable between the specimens examined, but not between the left and right sides of the same animal. The footplates of one Amblysomus specimen were broader than those of the other (Fig. 10A, B). The intercrural foramina in one Calcochloris specimen (Fig. 10C) and in the Angolan Huetia (Fig. 10D) were more triangular in shape than in the other specimens of these species. The stapes of the Angolan Huetia had a rounder articulation facet for the lenticular apophysis and a smaller footplate area than the Congo specimen (Table 4). The stapes footplates all fit relatively snugly within the oval windows. 


\section{Table 4}

Ossicular measurements in golden moles. Data are presented as means for all ears examined

(including both right and left ears from the same specimen, if data were available), with minimum and maximum values given underneath. In the case of Amblysomus, ossicular masses were directly measured by weighing. The lenticular apophysis may have been attached to either incus or stapes, according to specimen. In other species, masses were estimated from volume and density data (see Methods). All fossil mallei had broken manubria and anterior processes. The incudes had all lost their lenticular apophyses, and some had broken long processes. No fossil stapedes were found that could be attributed to golden moles, but the left oval window of Namachloris GSN Na 1 was measured from a CT reconstruction.

\begin{tabular}{|c|c|c|c|c|}
\hline Species/specimen & Malleus mass, mg & Incus mass, mg & Stapes mass, mg & $\begin{array}{l}\text { Stapes footplate area, } \\
\mathrm{mm}^{2}\end{array}$ \\
\hline $\begin{array}{l}\text { Amblysomus } \\
\text { hottentotus }\end{array}$ & $\begin{array}{c}0.94 \\
(0.93-0.96, n=4 \text { ears })\end{array}$ & $\begin{array}{c}0.90 \\
(0.88-0.91, n=4 \text { ears })\end{array}$ & $\begin{array}{c}0.08 \\
(0.08-0.09, n=4 \text { ears })\end{array}$ & $\begin{array}{c}0.59 \\
(0.57-0.60, \mathrm{n}=4 \text { ears })\end{array}$ \\
\hline $\begin{array}{l}\text { Calcochloris } \\
\text { obtusirostris }\end{array}$ & $\begin{array}{c}0.74 \\
(0.66-0.84, n=4 \text { ears })\end{array}$ & $\begin{array}{c}0.64 \\
(0.60-0.68, n=4 \text { ears })\end{array}$ & $\begin{array}{c}0.06 \\
(0.06-0.06, n=3 \text { ears })\end{array}$ & $\begin{array}{c}0.55 \\
(0.50-0.60, n=4 \text { ears })\end{array}$ \\
\hline $\begin{array}{l}\text { Huetia leucorhinus } \\
\text { (Angola specimen) }\end{array}$ & $\begin{array}{c}0.63 \\
(0.62-0.63, n=2 \text { ears })\end{array}$ & $\begin{array}{c}0.55 \\
(0.54-0.56, n=2 \text { ears })\end{array}$ & $\begin{array}{c}0.06 \\
(0.05-0.06, n=2 \text { ears })\end{array}$ & $\begin{array}{c}0.50 \\
(0.49-0.50, \mathrm{n}=2 \text { ears })\end{array}$ \\
\hline $\begin{array}{l}\text { Huetia leucorhinus } \\
\text { (Congo specimen) }\end{array}$ & $\begin{array}{c}0.77 \\
(0.75-0.80, n=2 \text { ears })\end{array}$ & $\begin{array}{c}0.54 \\
(0.54-0.54, n=2 \text { ears })\end{array}$ & $\begin{array}{c}0.08 \\
(0.08-0.08, n=2 \text { ears })\end{array}$ & $\begin{array}{c}0.61 \\
(0.61-0.62, n=2 \text { ears })\end{array}$ \\
\hline Fossil specimens & $\begin{array}{c}0.48 \\
(0.34-0.58, n=6)\end{array}$ & $\begin{array}{c}0.72 \\
(0.63-0.84, n=7)\end{array}$ & - & $\begin{array}{c}0.71 \\
\text { (oval window area) }\end{array}$ \\
\hline
\end{tabular}




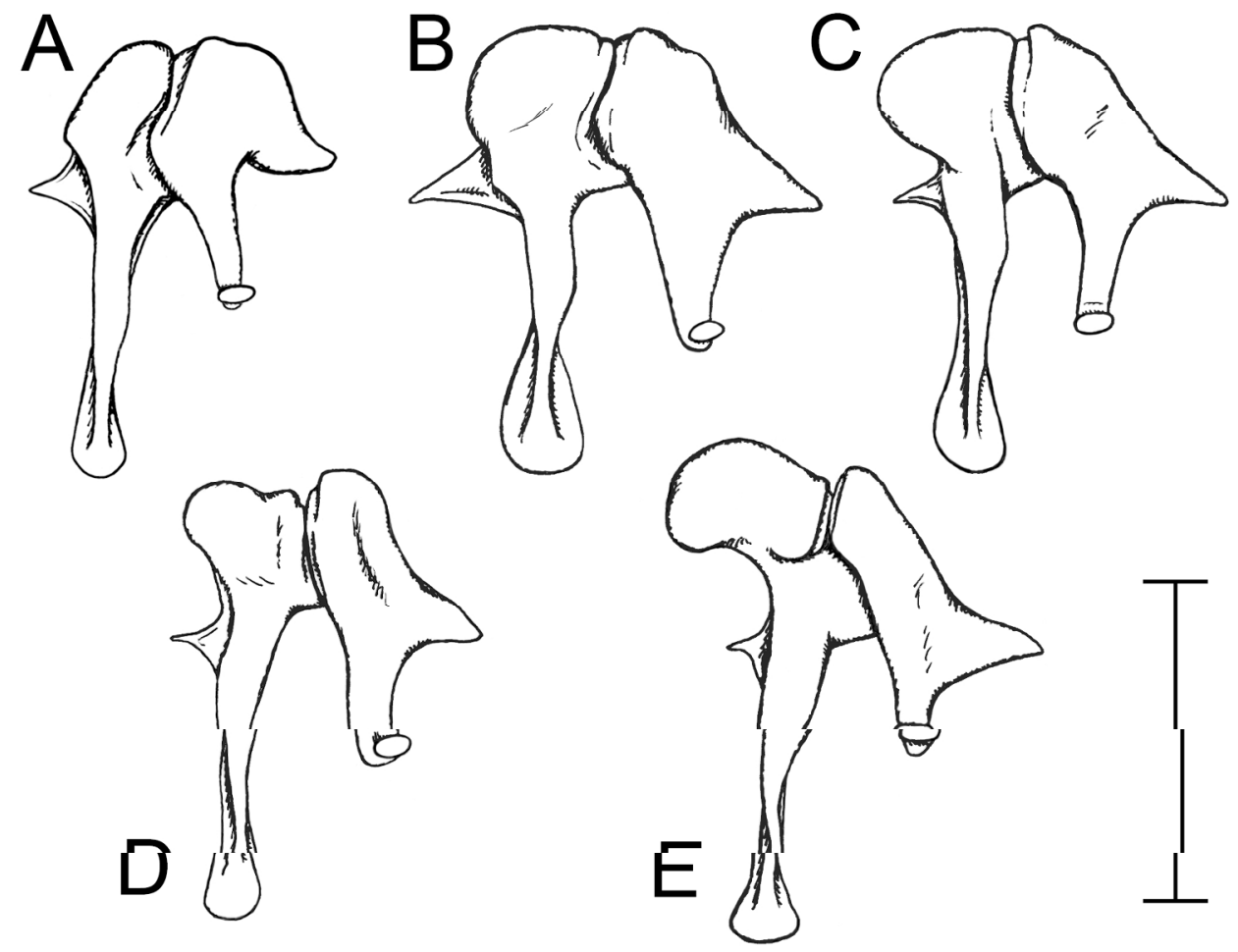

Fig. 9. Diagrammatic illustrations of right mallei and incudes, approximately medial views. A: malleus and incus attributed to Namachloris. All fossil ossicles were found separately, but for purposes of comparison these ossicles are drawn as if articulated. The manubrium, anterior process and lenticular apophysis, damaged or missing in the fossil specimens, have been reconstructed by comparison with the other species. B: Amblysomus; C: Calcochloris; D: Huetia, Angola specimen; E: Huetia, Congo specimen. Scale 


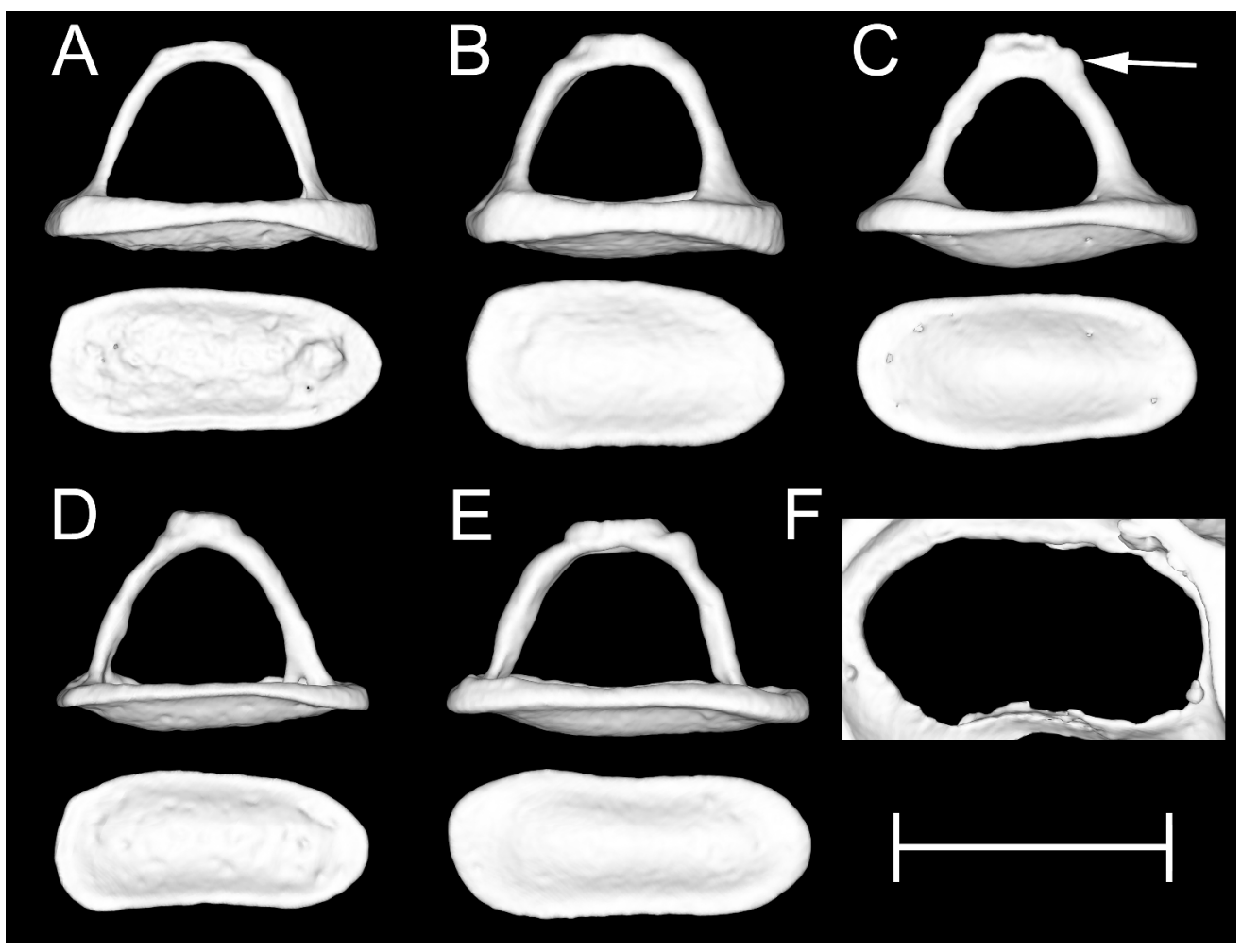

Fig. 10. CT reconstructions of stapedes and oval window in golden moles. The right stapes is seen in each case from an approximately dorsal view (top) and the vestibular side of its footplate is shown beneath. The arrow indicates the insertion point of the stapedius tendon. A, B: two specimens of Amblysomus; C:

Calcochloris; D: Huetia, Angola specimen; E: Huetia, Congo specimen. The vestibular side of the left oval window of Namachloris is shown in F. Scale bar $1 \mathrm{~mm}$.

$$
1483 \times 1123 \mathrm{~mm}(72 \times 72 \text { DPI) }
$$


The mallei attributed to Namachloris (Fig. 7A, 11) have relatively small, ovoid heads which are excavated posteriorly for articulation with the incudes. The articulation surface comprises two flattened and adjoining facets, set at an angle of around 120-130 degrees to each other. The articular surface narrows slightly where the two facets meet, such that, as seen from a posterior view, the articulation surface has a characteristic 'figure-of-eight' shape formed from the two angled facets. The upper facet is flat, whereas the lower is slightly convex. Anterior to the malleus head is the base of a laminar anterior process, which has broken off all specimens. A slender, slightly tapering neck joins the head to the manubrium. The manubrium was broken in most specimens but preserved almost intact in the malleus found within the middle ear cavity of GSN Na 1. It is triangular as seen from a posterior view, with a prominent lateral process (Fig. 11D). As in living species, its inserting and internal margins are both thickened with thin, laminar bone between them, giving the manubrium an I-beam shape in cross-section. Although there is some damage here, the inserting margin appears to expand only a little towards the tip, rather than flaring into a widely spatulate structure. There is a barely-discernible, slightly raised region on the medial side of the manubrium in two of the three specimens in which this part of the ossicle is preserved (Fig. 11A, D). Although this can hardly be described as a 'muscular process', it could represent the insertion point of a tensor tympani tendon.

Nine fossil incudes from Eocliff, all found loose, were taken to come from the same species as the fossil mallei. This was based on the fact that their articulation surfaces were the counterparts of those of the mallei, in terms both of the 'figure-of-eight' shape and the slight concavity of the lower facet (Fig. 12). Manually juxtaposing an incus to a malleus resulted in a good fit between the two ossicles; Figure 9A shows a composite diagram of what an intact ossicular pair may have looked like. The bodies of the fossil incudes were all stoutly constructed with a dorsal 'hump' at the base of the short process. The long process was narrow and tapering, bending medially towards its tip in those specimens in which it was not broken. No specimen retained a lenticular apophysis. The long process and body in some of these incudes were variably excavated. The smallest incus scanned had a larger 


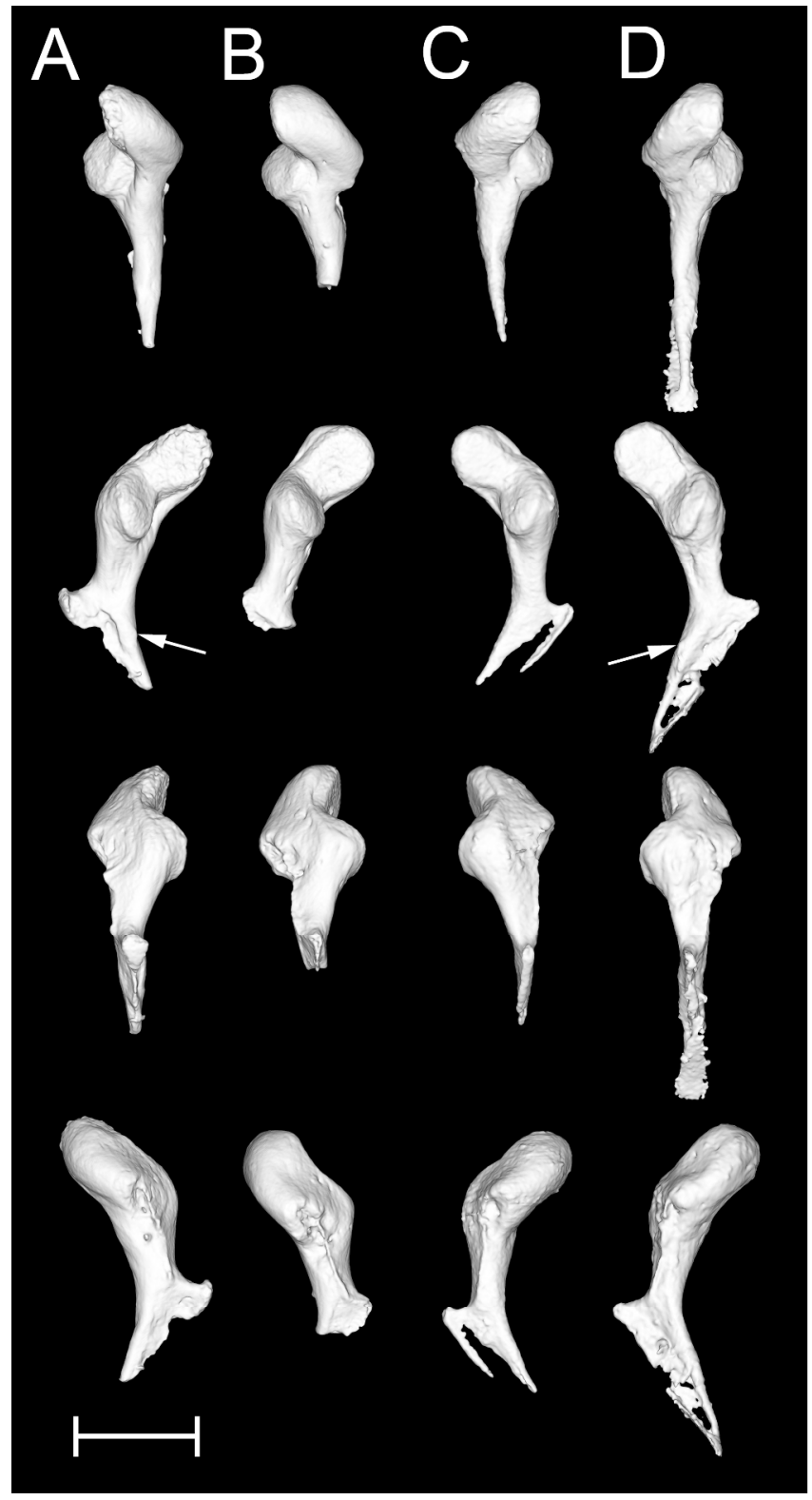

Fig. 11. CT reconstructions of four fossil mallei attributed to Namachloris, seen from approximately medial (upper row), posterior (second row), lateral (third row) and anterior (bottow row) views. The manubria are damaged to differing extents and none of these ossicles has an intact anterior process. Arrows point towards very slightly raised regions on two of the manubria which may represent the insertion sites of tensor tympani tendons. A: left malleus, GSN Na 7a; B: left malleus, GSN Na 101a; C: right malleus found in cranial cavity of GSN Na 1 skull; D: right malleus found in tympanic cavity of the same skull. Scale bar 1 $\mathrm{mm}$. 


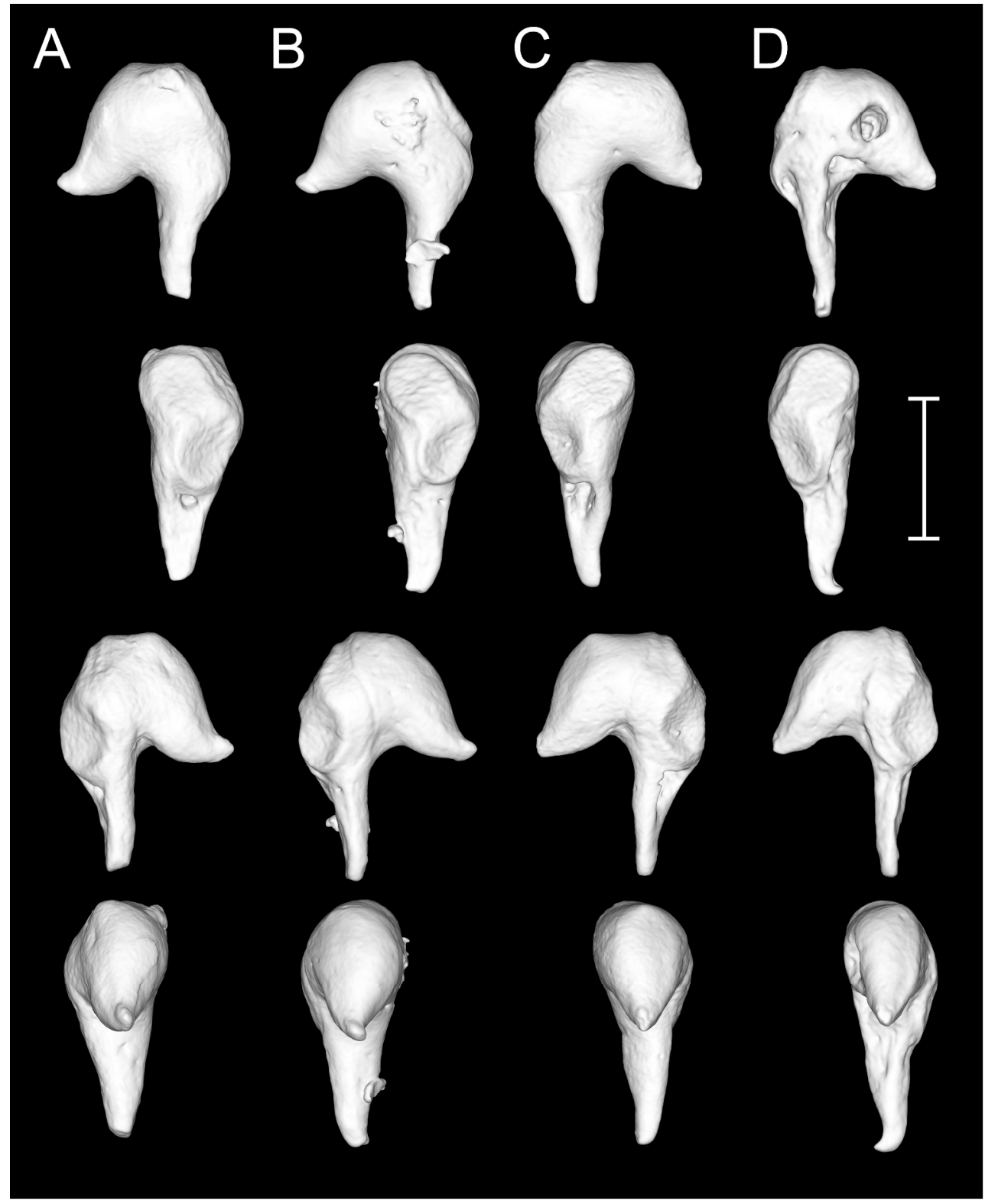

Fig. 12. CT reconstructions of four fossil incudes attributed to Namachloris, seen from approximately medial (upper row), anterior (second row), lateral (third row) and posterior (bottow row) views. The lenticular apophyses are missing in all cases. A: left incus, GSN Na 101b; B: left incus, GSN Na 120a; C: right incus, GSN Na 121a; D: right incus, GSN Na 120b. Scale bar $1 \mathrm{~mm}$. 


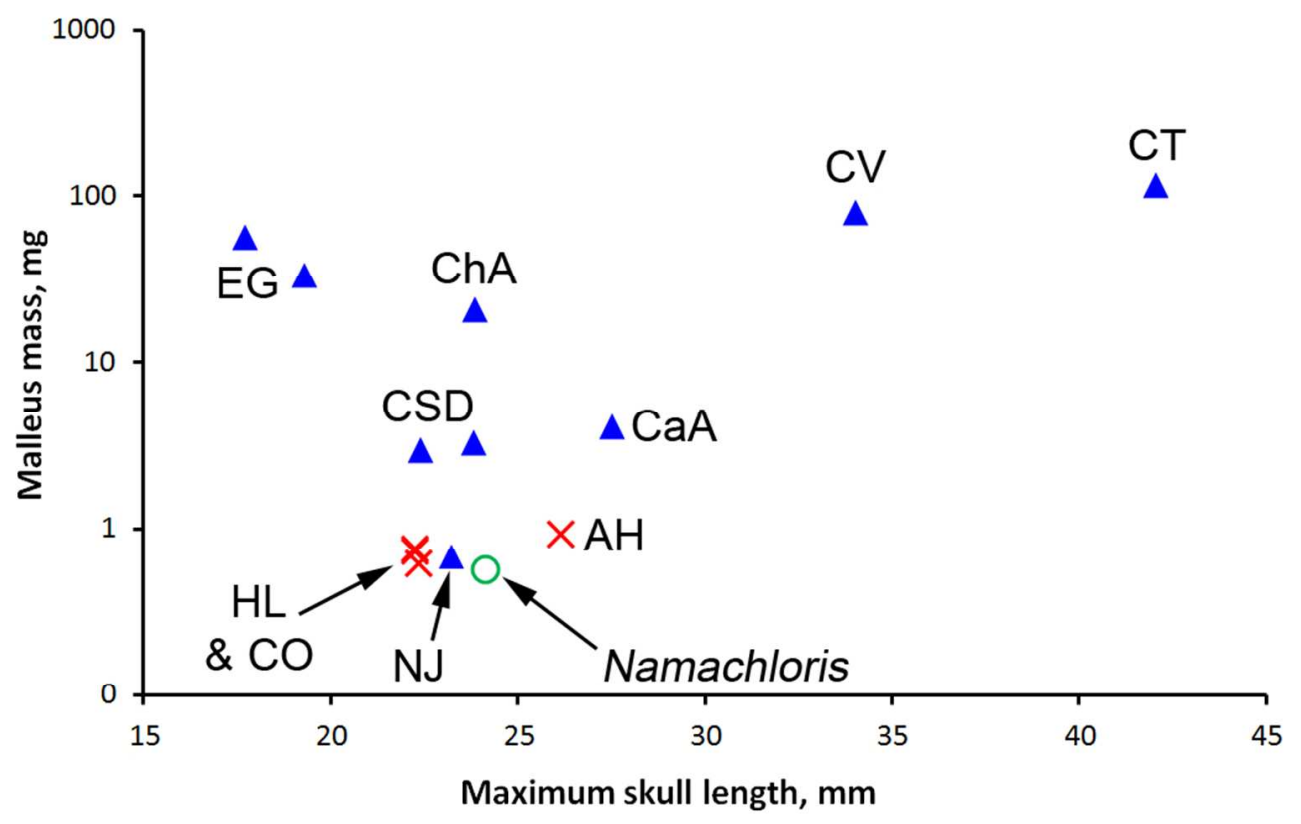

Fig. 13. Malleus mass plotted against maximum skull length in golden moles. Blue triangles = data obtained from another study (see Methods); red crosses = data obtained from extant species in present study; green circle = Namachloris. Malleus masses for Huetia, Calcochloris and Namachloris were estimated from ossicular volumes and Amblysomus densities. The data point for Namachloris was based on the mass of the malleus found in the middle ear cavity of fossil skull GSN $\mathrm{Na} 1$, and a maximum skull length estimated from a composite CT reconstruction. Key: $\mathrm{AH}=$ Amblysomus hottentotus; $\mathrm{CaA}=\mathrm{Carpitalpa}$ arendsi; $\mathrm{ChA}=$ Chrysochloris asiatica; $\mathrm{CO}=$ Calcochloris obtusirostris; CSD = Chlorotalpa sclateri and . . duthieae; $\mathrm{CT}=$ Chrysospalax trevelyani; $\mathrm{CV}=$ Chrysospalax villosus; $\mathrm{EG}=$ Eremitalpa granti granti and $\mathrm{E}$. g. namibensis; $\mathrm{HL}=$ Huetia leucorhinus; $\mathrm{NJ}=$ Neamblysomus julianae.

$371 \times 233 \mathrm{~mm}(72 \times 72 \mathrm{DPI})$ 
reconstructed volume than the largest malleus (Table 4): although all ossicles were damaged to some extent, the incus appears to be heavier than the malleus in this fossil species.

No stapedes were found that were attributable to Namachloris. The dimensions of the oval window suggest that it contained a broad footplate of similar area to those of the extant species (Fig. 10F; Table 4).

Amblysomus ossicular densities are presented in Table 3. Ossicular masses, measured directly or estimated from volumes and densities, are presented in Table 4 and are plotted against skull length in Fig. 13. No clear relationship between malleus mass and skull length is apparent across golden moles as a whole. The mallei of Amblysomus, Neamblysomus, Calcochloris, Huetia and Namachloris are all small in absolute terms. If malleus mass is divided by skull length cubed, these species also have the smallest ossicles in relative terms: Namachloris has the smallest of all, Amblysomus the smallest among the extant species.

\section{Inner ear morphology}

The structure of the bony labyrinth is very similar in Amblysomus, Calcochloris and Huetia species (Fig. 14A-C). The cochleae are tightly-coiled, with over three complete turns (Table 5). Calcochloris was found to have the longest cochlear duct and the most turns. The aspect ratio of height to basal width of the cochlear spiral was lowest in Huetia. The bony labyrinths of both Angola and Congo specimens of this species were very similar, but the Congo specimen had a more voluminous labyrinth and longer cochlear duct (Table 5).

Of the three semicircular canals of the extant species, the anterior canal is the longest. The lateral canal joins the posterior canal to form a short secondary crus commune (Fig. 6, 14), which widens at its base to form the posterior ampulla. This secondary crus commune is oval in cross-section and slightly grooved externally, such that the contributions of the lateral and posterior canals can be 


\section{Table 5}

Cochlear measurements in golden moles. The bony labyrinth volume measurement excludes the endolymphatic duct. Data are presented as means of all ears examined (including both right and left ears from the same specimen, if data were available), with minimum and maximum values given underneath. There was some damage to the bony labyrinths in most specimens of Calcochloris and Huetia, so the volumes presented are slight underestimates. Damage to the inner ears of the Namachloris specimen meant that the cochlear turns value is a rough estimate only, and measurements of duct length and labyrinth volume were not possible.

\begin{tabular}{|c|c|c|c|}
\hline Species/specimen & Cochlear turns & $\begin{array}{l}\text { Cochlear duct length, } \\
\mathrm{mm}\end{array}$ & $\begin{array}{l}\text { Bony labyrinth volume, } \\
\mathrm{mm}^{3}\end{array}$ \\
\hline $\begin{array}{l}\text { Amblysomus } \\
\text { hottentotus }\end{array}$ & $\begin{array}{c}3.19 \\
(3.08-3.28, n=4 \text { ears })\end{array}$ & $\begin{array}{c}9.84 \\
(9.70-9.94, n=4 \text { ears })\end{array}$ & $\begin{array}{c}4.26 \\
(3.92-4.63, n=4 \text { ears })\end{array}$ \\
\hline $\begin{array}{l}\text { Calcochloris } \\
\text { obtusirostris }\end{array}$ & $\begin{array}{c}3.47 \\
(3.32-3.66, n=4 \text { ears })\end{array}$ & $\begin{array}{c}10.34 \\
(10.12-10.50, n=4 \text { ears })\end{array}$ & $\begin{array}{c}3.38 \\
(3.16-3.61, n=4 \text { ears })\end{array}$ \\
\hline $\begin{array}{l}\text { Huetia leucorhinus } \\
\text { (Angola specimen) }\end{array}$ & $\begin{array}{c}3.15 \\
(3.09-3.20, n=2 \text { ears })\end{array}$ & $\begin{array}{c}8.79 \\
(8.75-8.82, n=2 \text { ears })\end{array}$ & $\begin{array}{c}3.42 \\
(3.40-3.43, n=2 \text { ears })\end{array}$ \\
\hline $\begin{array}{l}\text { Huetia leucorhinus } \\
\text { (Congo specimen) }\end{array}$ & $\begin{array}{c}3.25 \\
(3.21-3.28, n=2 \text { ears })\end{array}$ & $\begin{array}{c}9.52 \\
(9.45-9.58, n=2 \text { ears })\end{array}$ & $\begin{array}{c}4.34 \\
(4.21-4.47, n=2 \text { ears })\end{array}$ \\
\hline Namachloris GSN Na 1 & $3.2, n=1$ ear & - & - \\
\hline
\end{tabular}




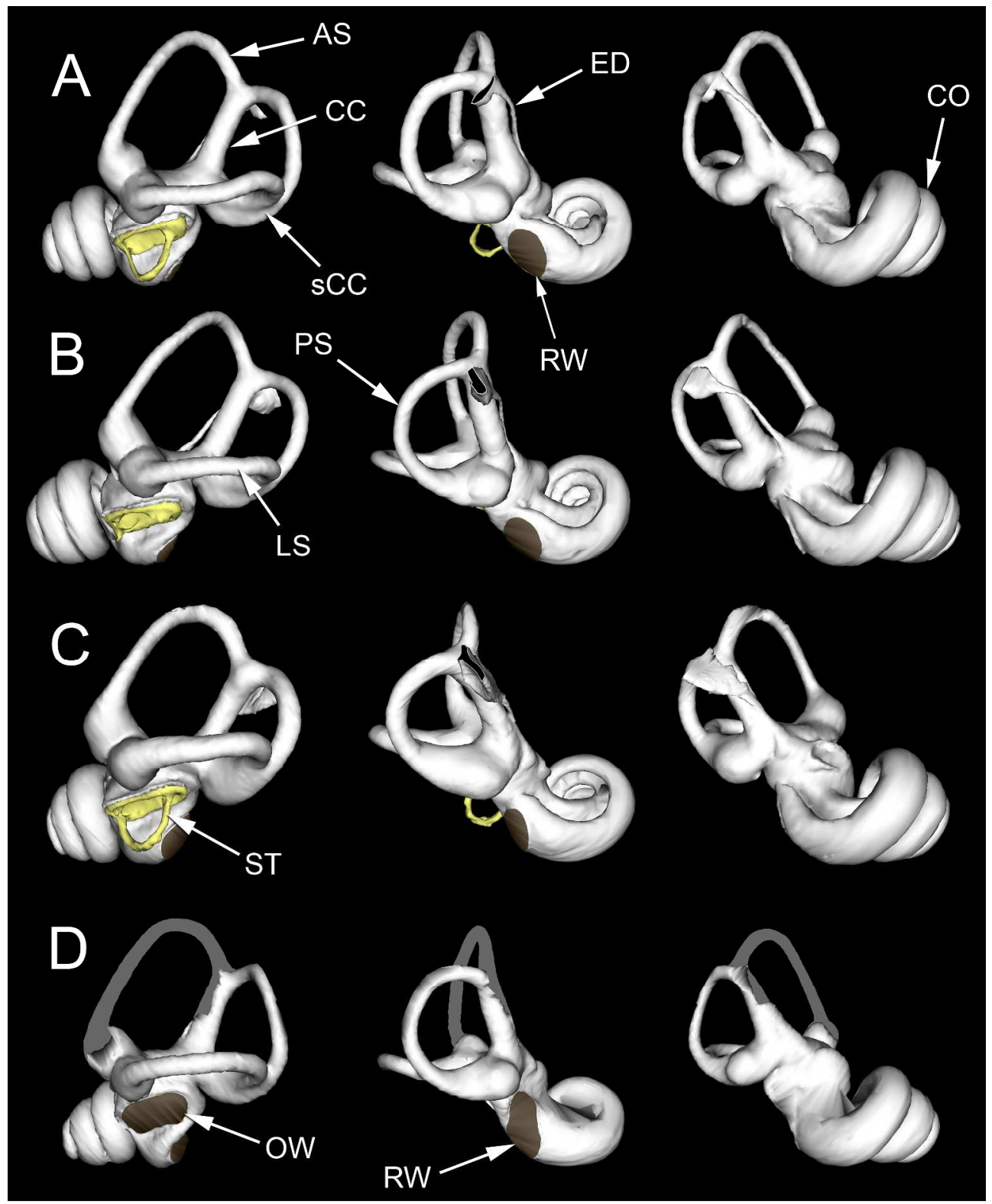

Fig. 14. WinSurf reconstructions of the left bony labyrinths of golden moles, seen from approximately (left) lateral, (middle) posterior and (right) medial views. Stapedes are shown in yellow, while oval and round windows have been shaded brown. A: Amblysomus; B: Calcochloris; C: Huetia, Congo specimen; D: Namachloris GSN Na 1. The stapes of Calcochloris has lost its crura, and that of Namachloris is missing. Namachloris is also lacking its anterior semicircular canal and endolymphatic duct. The putative position of its anterior canal is indicated in grey shading (based on Amblysomus). AS = anterior semicircular canal; $\mathrm{CC}=$ crus commune; $\mathrm{CO}=$ cochlea; $\mathrm{ED}=$ bony tube for endolymphatic duct; $\mathrm{LS}=$ lateral semicircular canal; $\mathrm{OW}=$ oval window; $\mathrm{PS}=$ posterior semicircular canal; $\mathrm{RW}=$ round window; $\mathrm{SCC}=$ secondary crus commune; ST = stapes. Not to scale. 
distinguished, but it is undivided internally. The semicircular canals of Huetia (Fig. 14C) were slightly wider relative to their radii of curvature than those of the other species.

The narrow bony tube for the endolymphatic duct arises from the anteromedial side of the base of the crus commune formed from anterior and posterior canals (Fig. 14). The duct runs alongside the crus, widens distally and opens just posterior to the crus into the cranial cavity. In Huetia, the tube for the duct remains in communication with the crus commune for longer, and it widens sooner than in the other species (Fig. 14C).

Facing essentially posteriorly in Amblysomus and Calcochloris but a little more posterolaterally in Huetia, the round window was located within its own small recess of the middle ear cavity, a recess largely free of trabeculae. The round window was smaller in area than the oval window and closer to being circular, these differences being least marked in Amblysomus (Fig. 14A). A discrete canaliculus cochleae for the perilymphatic duct was not found in any specimen. However, there was always a small foramen penetrating through the petrosal bone just posteromedial to the round window, uniting the recess for the round window with the cranial cavity.

The left bony labyrinth of Namachloris GSN Na 1 was more intact than the right. However, the anterior semicircular canal and endolymphatic duct canal were both missing through damage, and the internal structure of the cochlea including the bone around the modiolus was also missing. The reconstruction of what remains (Fig. 14D) is strikingly similar to the extant species, especially Amblysomus. As in all extant species, a secondary crus commune was formed between lateral and posterior semicircular canals. The height:width aspect ratio of the cochlea spiral was a little greater in Namachloris than in the extant species. The round window, facing in a largely posterior direction, was much more elongated in shape than in the extant species. Because it followed the walls of the bony labyrinth between the basal turn of the cochlea and the vestibule, it had a complex curvature, twisted $90^{\circ}$ about its long axis. It was similar in area to the oval window. It should be noted, however, that the exact position of the round window membrane is not easy to ascertain from CT 
scans if there is no air/fluid boundary, so our interpretation of its position and shape in Namachloris should be regarded with caution. No canaliculus cochleae could be identified, but the small foramen between round window recess and cranial cavity was present.

\section{Discussion}

Aside from aspects of the middle ear region which will be considered in detail later, cranial morphological characters used to identify and classify golden moles include dental formulae, the presence or absence of talonids on the lower cheek-teeth (Meester, 1974; Simonetta, 1968), and the relative positions of skull foramina (Asher et al., 2010). These characters will be briefly discussed here with reference to Namachloris and the other species examined.

The teeth of Namachloris have previously been described in detail: its dental formula was 3133/3133 and it had large talonids on the last lower premolar and molars (Pickford, 2015d). Most extant golden moles have ten teeth in each jaw quadrant, the exceptions being Calcochloris, Amblysomus and Neamblysomus species, which generally have nine (Meester, 1974; Skinner and Smithers, 1990). As expected, our Amblysomus and Calcochloris specimens had nine teeth, while both specimens of Huetia leucorhinus had ten. The presence of talonids is likely plesiomorphic for golden moles (Pickford, 2015d; Simonetta, 1968): they are said to be found on the third lower premolars and molars in most amblysomines, but they are absent in most chrysochlorines (Asher et

al., 2010). Prominent talonids were found in our Amblysomus specimens. Very small projections on the posterior faces of many of the lower cheek teeth, perhaps representing vestigial talonids, were found in both specimens of Calcochloris. The Angolan Huetia specimen had extremely small posterior projections on the first two premolars, but there was no trace in the Congo specimen. Dental characteristics can be variable within golden mole species: some specimens of $N$. gunningi 
have ten teeth per jaw quadrant, while some Huetia specimens have been found to lack the last molar (Meester, 1974). Such features are not considered diagnostic in distinguishing between suprageneric clades (Asher et al., 2010).

Turning to cranial foramina, Asher et al. (2010) found that the foramen ovale is narrowly separated from the foramen for the inferior ramus of the stapedial artery in amblysomines, Chlorotalpa and Calcochloris, while the two are confluent in chrysochlorines other than Calcochloris. Our findings agree with this. Reconstructions of the chrysochlorine Huetia show that the stapedial artery remains within a bony tube until it is very close to the foramen ovale; its inferior ramus presumably exits the skull through the foramen ovale directly. In Amblysomus and Calcochloris, a narrow bony bridge passes across the canal for the inferior ramus, separating its exit from the foramen ovale as seen from an external view. In Namachloris, unlike in extant golden moles, the exit-point of the inferior ramus is completely separate from the foramen ovale.

The foramen ovale was found to be well-separated from the sphenorbital fissure in amblysomines, but close together in chrysochlorines other than Huetia and Calcochloris (Asher et al., 2010). The situation in Chlorotalpa was variable. We have found that this feature correlates with middle ear cavity structure. Huetia and Calcochloris have extensively pneumatised and trabeculated basicrania, like amblysomines. The bony division between the foramen and fissure is inflated and pneumatized in these animals, which presumably contributes to widening the separation between them. This was also the case in Namachloris, which has a similar middle ear cavity structure.

\section{Middle ear cavity morphology}

Among amblysomines, Amblysomus has extensively trabeculated middle ear cavities which intercommunicate in the basisphenoid region, and this is also true of species of Neamblysomus (Mason, 2003b). Among chrysochlorines, Calcochloris and Huetia were shown here to have a similar 
cavity morphology. Given its widespread occurrence, it seems likely that this is plesiomorphic for crown-group golden moles. The chrysochlorines Chrysochloris and Eremitalpa have less trabeculated cavities featuring a single, wide channel connecting right and left ears (Mason, 2003b; Mason, 2016a). Chlorotalpa species have quite extensive trabeculae within their middle ear cavities (Mason, 2004), leading one to question whether the specimen with a simple channel depicted by von Mayer et al. (1995) might in fact have been misidentified. The cavity morphology in other golden moles has not been investigated in detail; Chrysospalax villosus is the only living species currently believed to lack an internal connection between left and right cavities (Mason, 2016a).

Among mammals other than golden moles, middle ears that intercommunicate within the basicranium have only been documented in certain talpid moles (see Mason, 2016a). This unusual characteristic must have evolved independently in these two distantly-related groups, perhaps to facilitate pressure-difference sound localisation (Coles et al., 1982). This is predicted to be advantageous to a small mammal which lacks pinnae and has hearing restricted to low frequencies, as is commonly the case in subterranean mammals (Mason, 2016a).

Namachloris had extensively trabeculated middle ear cavities, the pneumatized region extending dorsal to the root of the zygoma as in Calcochloris and Huetia. However, no basicranial intercommunication between left and right ears was found. Instead, the two sides were narrowly separated by a very thin, bony septum within the trabeculated basisphenoid, recalling the condition in the talpid mole Scalopus (Henson, 1974; Mason, 2006). Middle ear cavity expansion into neighbouring bones may have occurred in Namachloris to increase cavity compliance and thereby augment low-frequency hearing, but this had apparently not yet proceeded to the point where the dividing septum breaks down and the two cavities actually intercommunicate, as they do in extant species. Apparently pneumatized bone was also found to extend right around the brain in GSN Na 2, right and left sides meeting dorsally but not obviously intercommunicating. However, because the ear regions of GSN Na 2 were missing, it remains to be verified that the spongy bone above the brain 
in this specimen was indeed pneumatized by extensions of the middle ear cavities. The right and left cavities did not meet dorsally in GSN Na 1.

\section{Ossicle size}

Ossicular volumes in Calcochloris, Huetia and Namachloris were all below those of Amblysomus, the only exception being the stapes of the Congo Huetia which was similarly-sized. Volumes calculated using MicroView were on average $8.8 \%$ greater than those calculated using WinSurf ( $\mathrm{n}=49$ ossicles). Calculated densities of Amblysomus ossicles were accordingly lower using MicroView values (Table

3), but still compare favourably with mean values of $2.15 \mathrm{mg} \mathrm{mm}^{-3}$ for the malleus and $2.11 \mathrm{mg} \mathrm{mm}^{-3}$ for the incus of Amblysomus, measured experimentally in museum specimens (Mason et al., 2006). Calcochloris was found by Mason et al. (2006) to have similar malleus and incus densities to Amblysomus (2.08 and $2.14 \mathrm{mg} \mathrm{mm}^{-3}$ respectively); the highest density measured was that of the hypertrophied malleus of Eremitalpa, at $2.44 \mathrm{mg} \mathrm{mm}^{-3}$. Huetia was not examined in that study. Using the Amblysomus density values from Table 3, malleus masses for Calcochloris, Huetia and Namachloris are all calculated to be below those of Amblysomus (Table 4). Even using the Eremitalpa density value, the mallei of Calcochloris, Huetia and Namachloris are still calculated to weigh $1 \mathrm{mg}$ or below. Other golden moles of comparable body size have considerably larger mallei: over $3 \mathrm{mg}$ in Chlorotalpa and Carpitalpa species and many times that in Chrysochloris, Cryptochloris and Eremitalpa, to exceed 220 mg in one specimen of Chrysospalax villosus (Mason, 2003b; Mason et al., 2006; Fig. 1).

From mapping ossicular size onto available phylogenies, Asher et al. (2010) and Crumpton et al. (2015) suggested that the small ear ossicles found in golden moles such as Amblysomus might represent a derived morphology among crown-group chrysochlorids. Huetia was found to be the basal-most species of the group in one phylogenetic study (Bronner et al., 2012), so the size of its 
malleus is particularly significant. The malleus of Huetia has previously been regarded as "slightly enlarged" through the expansion of its head (Asher et al., 2010; Crumpton et al., 2015), in comparison with the small ossicles of Amblysomus and Calcochloris. The head of the malleus in our Congo specimen does look relatively large from a medial view (e.g. Fig. 7E), but it is mediolaterally compressed. The mallei of Huetia are in fact smaller in volume than those of Amblysomus, and are estimated to be among the smallest of any chrysochlorid in absolute mass (Fig. 13; Table 4). Among extant species, Amblysomus hottentotus has the smallest malleus relative to skull length cubed, but this relates in part to the relatively long, narrow skull characteristic of this species (Simonetta, 1968; see Fig. 2A).

The largest of the six fossil mallei found was the one from the middle ear cavity of Namachloris GSN $\mathrm{Na} 1$, which was the most intact. Its estimated mass $(0.58 \mathrm{mg})$ is lower than in any extant species, and it is also smaller than any of the incudes believed to come from the same fossil species (Table 4). The incus is normally smaller than the malleus in golden moles, although it can be slightly larger in Amblysomus (Mason, 2003b). It should be borne in mind that all fossil mallei were damaged, even the largest lacking an anterior process and having a damaged manubrium, but the difference that the loss of these processes make to the mass would be relatively small. Even if this malleus type were not from Namachloris, the available space within the middle ear cavity of GSN Na 1 confirms that this was a 'small ossicle' species.

The contention that malleus hypertrophy is plesiomorphic for living golden moles is weakened by our findings that neither Huetia nor Namachloris have significantly enlarged mallei, in absolute terms. Amblysomus and Calcochloris, an amblysomine and a chrysochlorine respectively, have remarkably similar ossicles and indeed ear structures in general. There is no morphological indication that their small ossicles evolved convergently from a hypertrophied ancestral state. 


\section{The ossicles of Huetia}

The skulls, middle ear cavities and inner ears of our two specimens of Huetia leucorhinus were morphologically very similar. However, the ossicles of these two animals were notably different, most conspicuously in the degree of expansion of the malleus head (see Results). Intraspecific differences in ossicular structure could relate to age or size, but our two skulls were of almost identical maximum length. Among golden moles, intraspecific variability in malleus morphology has previously been documented in Eremitalpa granti, in which the malleus head differs markedly in both shape and size between the two recognised subspecies, granti and namibensis (Mason et al., 2006). Could our Huetia specimens also represent different subspecies?

Two subspecies of Huetia (formerly Calcochloris) leucorhinus are currently recognised, $H$. I. leucorhinus and H. I. cahni (Bronner, 2013). The collection locations of our specimens were relatively close: north-east Angola and south-west Democratic Republic of the Congo, both within the geographical range cited by Bronner for H. I. leucorhinus. Crumpton et al. (2015) show a CT reconstruction of another Huetia malleus, from a skull housed in the Muséum National d'Histoire Naturelle, Paris. This specimen was collected in the Central African Republic, within the cited range of $H$. I. cahni. The reconstruction lacks anterior process and manubrium tip, but the malleus headshape resembles that of our Congo specimen.

Morphologically, H. I. leucorhinus is said to be distinguished from H. I. cahni through having less triangular molars, an unreduced lacrimal foramen (Schwarz and Mertens, 1922) and well-developed talonids on its lower premolars (Bronner, 2013). The lacrimal foramina did not seem unusually small in either of our two specimens and neither had well-developed talonids, although what may have been vestigial talonids were found in the Angola specimen. If the Angola specimen was in fact $H$. I. leucorhinus and the Congo specimen H. I. cahni, malleus head shape may prove to be a more reliable distinguishing characteristic than those mentioned above. Alternatively, the ossicular differences 
may reflect a hitherto unrecognised division within the Huetia genus, or simply an unusual amount of individual variation.

Although not significantly enlarged in absolute terms, the morphology of the Huetia malleus, especially in the Congo specimen, is certainly unusual. Displacement of the centre of ossicular mass away from the rotatory axis is important in increasing the response to head vibrations (Mason, 2003a), suggesting that the shape of the Huetia malleus might represent an early stage in the development of sensitive bone-conducted hearing. Ossicular hypertrophy is widely suspected to have evolved multiple times within golden moles (Asher et al., 2010; Mason, 2003b; von Mayer et al., 1995), perhaps because their digging mechanism involves close contact between the head and the substrate, preadapting these animals to the detection of ground vibrations (Mason and Narins, 2001).

In the present study, intraspecific differences in stapes morphology were observed in Amblysomus, Calcochloris and Huetia specimens. Larger differences have been documented between the stapedes of different chromosomal species of the spalacid mole-rat Spalax ehrenbergi (Burda, Bruns and Nevo, 1989; Mason, Lai, Li and Nevo, 2010) and in certain bathyergid mole-rats (Burda, Bruns and Hickman, 1992; Mason et al., 2016). Whether stapedial variation among fossorial mammals reflects relaxed selective pressure on this ossicle remains unknown.

\section{Fossil ossicles}

Pickford (2015d) attributed incudes of the type shown in Fig. 12 to Namachloris arenatans. Two mallei also attributed to this species were listed but not described. Nearly all of the other ossicles recovered from the same fossil sites are from Ctenohystrica-group rodents (Mason et al., in preparation), and have a very different morphology. Adding weight to Pickford's attribution, we found two right mallei, with cognate articular surfaces to those of the incudes, closely associated 
with the GSN Na 1 skull, one in the right middle ear cavity. Access was narrow, but it is conceivable that the malleus found in the middle ear cavity worked its way in through the broken external walls. Therefore, although it is most parsimonious to assume that this malleus and the very similar one found in the cranial cavity, and therefore the incudes too, were from Namachloris, we cannot be absolutely sure of this. Factors in agreement with the hypothesis that these are Namachloris ossicles include:

1) The "freely mobile" malleus morphology, featuring a relatively large head and delicate anterior process (Fleischer, 1978). There is no sign of an orbicular apophysis, nor the characteristic rostral inclination of the manubrium relative to the ossicular neck which would suggest a "microtype" ancestry. Golden mole species which lack malleus hypertrophy also have freely-mobile ossicles.

2) The 'figure-of-eight' shaped malleoincudal articulation, composed of two relatively flat facets. Flattened articulations are a characteristic feature of subterranean mammals (Burda et al., 1992; Segall, 1973), including golden moles. The malleoincudal articulation tends towards a 'figure-of-eight' shape in Calcochloris and Huetia.

3) Only two out of three fossil mallei with intact proximal manubria showed any trace of a tensor tympani insertion. Extant golden moles lack this muscle and hence also lack muscular processes, but this is otherwise unusual among mammals (see below).

The proposed Namachloris ossicles differ from those of extant golden moles in other respects, however. The fossil malleus heads are much less pronounced than in any extant chrysochlorid. They have more prominent, bony lateral processes than Amblysomus and Calcochloris, and also narrower, apparently non-spatulate manubria. Huetia is closer to the fossil species in these respects. The fossil incudes are more bulbous in shape than in extant golden moles, in which the incudal bodies appear more 'stretched-out' (Fig. 8). 
No stapedes were found that could be attributed to Namachloris, but the oval window area of GSN Na 1 was a similar shape and size to the stapes footplates of the extant species (Fig. 10, Table 4). Its area may have been slightly overestimated due to damage to its borders. From the regression equation given by Mason (2001), the expected stapes footplate area of a non-fossorial mammal the size of Amblysomus ( $68 \mathrm{~g}$ ), the largest of the species considered here, would be $0.28 \mathrm{~mm}^{2}$. The stapes footplates of Amblysomus, Calcochloris and Huetia, and the oval window of Namachloris, are all much larger than this (Table 4). Large stapes footplates are characteristic of many fossorial mammals (Burda et al., 1992; Mason, 2001). Crumpton et al. (2015) reported that chrysochlorids have relatively larger footplates than talpid moles or tenrecs, but did not find a significant difference between fossorial and terrestrial groupings. However, their comparison calculated footplate areas as rectangles and divided them by the square-root of body mass, which would yield a size-dependent ratio under the assumption of isometry, so the meaning of these results is unclear.

\section{Middle ear muscles}

Our interpretation that Namachloris possessed a small tensor tympani muscle is based on the presence of a fossa for the muscle belly running between stapedial and promontorial arteries. CT scans made of the sengis Elephantulus and Macroscelides (Mason, 2016b) show a fossa containing the tensor tympani in exactly the same position. Unlike the sengis, the fossil mallei attributed to Namachloris lacked prominent muscular processes, although two showed the barest trace of a muscle insertion. This suggests that the tensor tympani was very weak, as in certain talpid moles and the hamster Mesocricetus, which also have very small or absent muscular processes (Lavender, Taraskin and Mason, 2011; Mason, 2006). Although vestiges of the muscle have been described in embryos (Findlay, 1944; Forster Cooper, 1928), no extant chrysochlorid has been found to possess a tensor tympani as an adult (Mason, 2003b; 2004; 2007; von Mayer et al., 1995). The loss of this 
muscle in golden moles is clearly associated with the convergence of the stapedial and promontorial arteries beyond the pelvis ovalis.

Earlier reports that the stapedius muscle in golden moles is reduced to a ligament without muscle fibres (Mason, 2003b; von Mayer et al., 1995) are erroneous. Although Mason (2003b) failed to identify the muscle belly in serial sections of Chrysochloris asiatica belonging to the University Museum of Zoology, Cambridge, subsequent study of the same sections has confirmed its presence. Bony tubes for the stapedius muscle belly were clearly identifiable in the CT scans of all golden moles examined in the present study, including Namachloris.

\section{Inner ears}

The golden moles investigated here had between 3 and 3.5 cochlear turns (Table 5), relatively high values for mammals in general but consistent with previous reports (Benoit, Orliac and Tabuce, 2013b; Crumpton et al., 2015; Ekdale, 2013; von Mayer et al., 1995). It was difficult to assess the number of turns accurately in Namachloris because the internal structure of the cochlea was missing on both sides, but the grooves in its outer shell suggested that this animal also had a number within this range. This supports the conclusion of Crumpton et al. (2015) that a highly-coiled cochlea is plesiomorphic for crown-group chrysochlorids. The height:width aspect ratio of the cochlear spiral in Namachloris was slightly greater than in the extant species and the round window appeared to have a more elongated shape, but the general morphology of the bony labyrinth was otherwise very similar.

A small mammal may need a high degree of cochlear coiling in order to accommodate a relatively long basilar membrane (Davies, Maryanto and Rossiter, 2013). Golden moles have long cochlear

relatives in particular (Crumpton et al., 2015). Although a relatively long duct presumably reflects the 
importance of hearing to golden moles, it is difficult to interpret in terms of frequency sensitivity because, as Crumpton et al. point out, highly-coiled cochleae are also found in caviomorph rodents (Pye, 1977) and some echolocating bats (Davies et al., 2013; Pye, 1970), which have very different frequency ranges of interest.

The bony labyrinth in every golden mole examined here, including Namachloris, possessed a secondary crus commune formed by the fusion of the bony tubes for the lateral and posterior semicircular canals. According to Ekdale (2013), this represents the ancestral condition for both Theria and Eutheria but not for Placentalia, in which entry of the lateral semicircular canal directly into the vestibule is regarded as "the single unambiguous otic synapomorphy". Our findings are contrary to the description of the inner ear in Chrysochloris sp. given by Ekdale, who found that this golden mole had the ancestral placental condition. A secondary common crus is lacking in extant Tenrecidae and Macroscelidea but it was present in the supposed elephant-shrew Chambius from the early-mid Eocene (Benoit et al., 2013b), as well as other afrotherians including Orycteropus (Ekdale, 2013), an unnamed stem sirenian (Benoit et al., 2013b), and the stem proboscidians Numidotherium and Phosphatherium (Benoit, Merigeaud and Tabuce, 2013a; Schmitt and Gheerbrant, 2016). It seems possible that the presence of a secondary common crus in chrysochlorids is a retained characteristic, plesiomorphic for Afrotheria as a whole but secondarily lost in many extant groups. Chrysochloris should be re-examined to confirm Ekdale's interpretation.

In typical mammals, the perilymphatic foramen of the embryo separates into the round window and canaliculus cochleae (Fischer, 1990). The round window, covered by a thin membrane which separates inner ear fluids from the air of the middle ear cavity, is seen as a pressure-release point to allow the displacement of the cochlear fluids in response to movements of the stapes. The canaliculus cochleae is a narrow tube through the petrosal bone which conveys the perilymphatic duct, uniting the inner ear with the subarachnoid space. A discrete canaliculus cochleae is lacking in extant elephants and sirenians, in which the perilymphatic duct and round window are confluent 
(Ekdale, 2013; Fischer, 1990; Fleischer, 1973). Fossil evidence suggests that this condition was acquired convergently (Court and Jaeger, 1991; Schmitt and Gheerbrant, 2016). A similar morphology has been described in the extinct embrithopod Arsinoitherium (Court, 1990), also an afrotherian, some pinnipeds (Wyss, 1987) and the grey whale Eschrichtius (Ekdale, Berta and Deméré, 2011; Geisler and Luo, 1996). We were unable to identify a canaliculus cochleae in any golden mole. The perilymphatic duct might potentially emerge from the round window to enter the cranial cavity through the small foramen in the medial wall of the round window recess, but there is no bony groove to mark its passage. Our interpretation of the morphology of this region differs from that of Ekdale (2013), who reconstructed what appears to be the round window recess in Chrysochloris as an outpocketing of the perilymphatic sac, and showed the canaliculus cochleae emerging from this. Confirmation of the presence and position of the perilymphatic duct in golden moles will require examination of histological sections.

\section{Conclusions}

There is no reason to imagine that all the characteristics of the Palaeogene golden mole Namachloris must be primitive, just because of its age. For example, spongy, trabeculated bone was found to extend dorsally all the way around the brain in one of the two specimens examined, a feature not described in any extant golden mole. The peculiarly bulbous incus attributed to this fossil species is also unique among chrysochlorids. Similarly, even if Huetia is accepted as the basal-most living genus of chrysochlorid, this does not mean that it cannot be derived in some respects, for example in its unusual malleus morphology which may represent an incipient adaptation towards bone-conducted hearing. A more rigorous analysis of the evolution of the auditory region of golden moles must await the publication of a well-supported phylogenetic tree, onto which characteristics can be mapped. However, based on our observations of middle ear morphology, we tentatively propose that 
Namachloris lies outside of crown-group Chrysochloridae, and that the following are plesiomorphic features of the clade consisting of Namachloris plus the crown-group:

1) Extensively pneumatized, trabeculated middle ear cavities, the pneumatization extending into the basicranium and also around the lateral aspect of the skull, posterior to the zygomatic arch.

2) Arteries and nerves of the middle ear confined within bony tubes.

3) A tightly-spiralled cochlea with three or more turns.

4) A secondary crus commune uniting posterior and lateral semicircular canals.

5) No distinct canaliculus cochleae.

6) A relatively large stapes footplate and oval window.

7) A wide hiatus facialis.

8) A small malleus with a prominent lateral process and a manubrium which is not broadly spatulate.

9) A flattened malleo-incudal articulation with two facets.

10) Retention of a tensor tympani muscle, which separates promontorial and stapedial arteries.

11) Left and right middle ear cavities which do not intercommunicate.

Of these, features (1) to (6) are features of extant golden moles in general; (7) to (9) are not universal but are found in Huetia. Points (10) and (11) are found in Namachloris alone among golden moles, but are likely plesiomorphic for Afrotheria.

We further propose that the following are synapomorphies of crown-group chrysochlorids, distinguishing them from Namachloris:

1) Intercommunication of left and right middle ear cavities within the basisphenoid. The open channel uniting middle ear cavities in some genera (e.g. Chrysochloris and Eremitalpa) likely 
represents a modification of the ancestral union within spongy bone. This

intercommunication appears to have been lost in Chrysospalax.

2) Loss of the tensor tympani muscle, allowing the stapedial and promontorial arteries to converge beyond the pelvis ovalis.

3) Convergence of the exit-point of the inferior ramus of the stapedial artery with the foramen ovale.

4) A more circular round window.

\section{Acknowledgements}

We would like to acknowledge the help of Paula Jenkins and Roberto Portela Miguez in facilitating the loan of material from The Natural History Museum. The Cambridge Biotomography Centre kindly allowed used of their scanner facilities. The authors are very grateful to Gary Bronner and Sandra Goutte for providing help and advice. MP thanks the Geological Survey of Namibia (Gabi Schneider, Gloria Simubali, Anna Nguno, Vicky Do Cabo, Helke Mocke, Jane Eiseb, Ute Schreiber) for support and encouragement to carry out geological research in Namibia, the National Heritage Council of Namibia (Erica Ndalikokule, Helvi Elago) for research authorisation and for the temporary export permit for preparation and study of the fossils, Namdeb Ore Reserves Department (J.J. Jacob, Hester Fourie) for financial and logistic support, the French Ministry of Foreign Affairs for financial support, the Muséum National d'Histoire Naturelle, Paris (Brigitte Senut, Christine Lefèvre, Violaine Nicolas) for logistic and financial support and for arranging access to osteological collections, the French CNRS and the University of Rennes (François Guillocheau) for financial aid. This work was partially funded by a National Research Foundation grant to NCB. All images reconstructed from Natural History Museum specimens are shown courtesy of the Trustees of the Natural History Museum, 
London. The authors would like to thank the three reviewers of this manuscript for their constructive comments.

\section{References}

Asher, R.J. (2010). Tenrecoidea. In: Werdelin L, Sanders WJ, editors. Cenozoic Mammals of Africa. Berkeley: University of California Press. pp. 99-106.

Asher, R.J., Avery, D.M. (2010). New golden moles (Afrotheria, Chrysochloridae) from the Early Pliocene of South Africa. Palaeontologia Electronica, 13, 3A.

Asher, R.J., Maree, S., Bronner, G., Bennett, N.C., Bloomer, P., Czechowski, P., Meyer, M., Hofreiter, M. (2010). A phylogenetic estimate for golden moles (Mammalia, Afrotheria, Chrysochloridae). BMC Evolutionary Biology, 10, 69.

Beck, R.M.D., Bininda-Emonds, O.R.P., Cardillo, M., Liu, F.-G.R., Purvis, A. (2006). A higher-level MRP supertree of placental mammals. BMC Evolutionary Biology, 6, doi 10.1186/1471-2148-11861193.

Benoit, J., Merigeaud, S., Tabuce, R. (2013a). Homoplasy in the ear region of Tethytheria and the systematic position of Embrithopoda (Mammalia, Afrotheria). Geobios, 46, 357-370.

Benoit, J., Orliac, M., Tabuce, R. (2013b). The petrosal of the earliest elephant-shrew Chambius (Macroscelidea: Afrotheria) from the Eocene of Djebel Chambi (Tunisia) and the evolution of middle and inner ear of elephant-shrews. Journal of Systematic Palaeontology, 11, 907-923.

Bronner, G.N. (2013). Calcochloris leucorhinus Congo golden-mole. In: Kingdon J, Happold DCD, Butynski TM, Hoffmann M, Happold M, Kalina J, editors. Mammals of Africa, vol 1 Introductory Chapters and Afrotheria. London: Bloomsbury. pp. 234-235. 
Bronner, G.N., Maree, S., Bloomer, P., Bennett, N., Asher, R., Mason, M. (2012). Unique middle ear morphologies of golden moles: riddled by homoplasy. Program \& Abstracts of the American Society of Mammalogists, 92nd Annual Meeting, 94-95.

Broom, R. (1941). On two Pleistocene golden moles. Annals of the Transvaal Museum, 20, 215-216.

Burda, H., Bruns, V., Hickman, G.C. (1992). The ear in subterranean Insectivora and Rodentia in comparison with ground-dwelling representatives. I. Sound conducting system of the middle ear. Journal of Morphology, 214, 49-61.

Burda, H., Bruns, V., Nevo, E. (1989). Middle ear and cochlear receptors in the subterranean molerat, Spalax ehrenbergi. Hearing Research, 39, 225-230.

Butler, P.M. (1984). Macroscelidea, Insectivora and Chiroptera from the Miocene of East Africa. Palaeovertebrata, 14, 117-200.

Butler, P.M., Hopwood, A.T. (1957). Insectivora and Chiroptera from the Miocene rocks of Kenya Colony. Fossil Mammals of Africa, 13, 1-35.

Coles, R.B., Gower, D.M., Boyd, P.J., Lewis, D.B. (1982). Acoustic transmission through the head of the common mole, Talpa europaea. Journal of Experimental Biology, 101, 337-341.

Coster, P., Benammi, M., Mahboubi, M., Tabuce, R., Adaci, M., Marivaux, L., Bensalah, M., Mahboubi, S., Mahboubi, A., Mebrouk, F., Maameri, C., Jaeger, J.-J. (2012). Chronology of the Eocene continental deposits of Africa: Magnetostratigraphy and biostratigraphy of the El Kohol and Glib Zegdou Formations, Algeria. Geological Society of America Bulletin, 124, 1590-1606.

Court, N. (1990). Periotic anatomy of Arsinoitherium (Mammalia, Embrithopoda) and its phylogenetic implications. Journal of Vertebrate Paleontology, 10, 170-182.

Court, N., Jaeger, J.-J. (1991). Anatomy of the periotic bone in the Eocene proboscidean Numidotherium koholense: an example of parallel evolution in the inner ear of tethytheres. Comptes rendus de l'Académie des sciences Série II, Mécanique, physique, chimie, sciences de I'univers, sciences de la terre 312, 559-565. 
Crumpton, N., Kardjilov, N., Asher, R.J. (2015). Convergence vs. specialization in the ear region of moles (Mammalia). Journal of Morphology, 276, 900-914.

Davies, K.T.J., Maryanto, I., Rossiter, S.J. (2013). Evolutionary origins of ultrasonic hearing and laryngeal echolocation in bats inferred from morphological analyses of the inner ear. Frontiers in Zoology, 10, DOI: 10.1186/1742-9994-1110-1182.

De Graaff, G. (1958). A new chrysochlorid from Makapansgat. Palaeontologia Africana, 5, 21-27.

Ekdale, E.G. (2013). Comparative anatomy of the bony labyrinth (inner ear) of placental mammals PLoS One, 8, e66624.

Ekdale, E.G., Berta, A., Deméré, T.A. (2011). The comparative osteology of the petrotympanic complex (ear region) of extant baleen whales (Cetacea: Mysticeti). PLoS One, 6, e21311.

Findlay, G.H. (1944). The development of the auditory ossicles in the elephant shrew, the tenrec and the golden mole. Proceedings of the Zoological Society of London, 114, 91-99.

Fischer, M.S. (1990). Un traite unique de l'oreille des éléphants et des siréniens (Mammalia): un paradoxe phylogénétique. Comptes Rendus des Séances de l'Académie des Sciences, série III, Sciences de la Vie, 311, 157-162.

Fleischer, G. (1973). Studien am Skelett des Gehörorgans der Säugetiere, einschließlich des Menschen. Säugetierkundliche Mitteilungen, 21, 131-239.

Fleischer, G. (1978). Evolutionary principles of the mammalian middle ear. Advances in Anatomy, Embryology and Cell Biology, 55, 1-70.

Forster Cooper, C. (1928). On the ear region of certain of the Chrysochloridae. Philosophical Transactions of the Royal Society of London B, 216, 265-283.

Geisler, J.H., Luo, Z. (1996). The petrosal and inner ear of Herpetocetus sp. (Mammalia: Cetacea) and their implications for the phylogeny and hearing of archaic mysticetes. Journal of Paleontology, 70, 1045-1066. 
Henson, O.W. (1974). Comparative anatomy of the middle ear. In: Keidel WD, Neff WD, editors. Handbook of Sensory Physiology, volume V/1: Auditory System. Berlin: Springer-Verlag. pp. 39-110.

Kuntner, M., May-Collado, L.J., Agnarsson, I. (2011). Phylogeny and conservation priorities of afrotherian mammals (Afrotheria, Mammalia). Zoologica Scripta, 40, 1-15

Lavender, D., Taraskin, S.N., Mason, M.J. (2011). Mass distribution and rotational inertia of "microtype" and "freely mobile" middle ear ossicles in rodents. Hearing Research, 282, 97 107.

Lombard, R.E., Hetherington, T.E. (1993). Structural basis of hearing and sound transmission. In: Hanken J, Hall BK, editors. The Skull. Chicago: The University of Chicago Press Ltd. pp. 241302.

Marivaux, L., Essid, E.M., Marzougui, W., Ammar, H.K., Adnet, S., Marandat, B., Merzeraud, G., Tabuce, R., Vianey-Liaud, M. (2014). A new and primitive species of Protophiomys (Rodentia, Hystricognathi) from the late middle Eocene of Djebel el Kébar, Central Tunisia. Palaeovertebrata, 38 (1)-e2, 1-17.

Marivaux, L., Lihoreau, F., Manthi, F.K., Ducrocq, S. (2012). A new basal phiomorph (Rodentia, Hystricognathi) from the late Oligocene of Lokone (Turkana Basin, Kenya). Journal of Vertebrate Paleontology, 32, 646-657.

Mason, M.J. 1999. The Functional Anatomy of the Middle Ear of Mammals, with an Emphasis on Fossorial Forms [PhD]. Cambridge, UK: University of Cambridge.

Mason, M.J. (2001). Middle ear structures in fossorial mammals: a comparison with non-fossorial species. Journal of Zoology, 255, 467-486.

Mason, M.J. (2003a). Bone conduction and seismic sensitivity in golden moles (Chrysochloridae). Journal of Zoology, 260, 405-413.

Mason, M.J. (2003b). Morphology of the middle ear of golden moles (Chrysochloridae). Journal of Zoology, 260, 391-403. 
Mason, M.J. (2004). Functional morphology of the middle ear in Chlorotalpa golden moles (Mammalia, Chrysochloridae): predictions from three models. Journal of Morphology, 261, 162-174.

Mason, M.J. (2006). Evolution of the middle ear apparatus in talpid moles. Journal of Morphology, $267,678-695$.

Mason, M.J. (2007). Massive mallei in moles: middle ear adaptations subserving seismic sensitivity. Proceedings of the Institute of Acoustics, 29, 69-76.

Mason, M.J. (2013). Of mice, moles and guinea-pigs: functional morphology of the middle ear in living mammals. Hearing Research, 301, 4-18.

Mason, M.J. (2016a). Internally coupled ears in living mammals. Biological Cybernetics, 110, 345-358.

Mason, M.J. (2016b). Structure and function of the mammalian middle ear. I: Large middle ears in small desert mammals. Journal of Anatomy, 228, 284-299.

Mason, M.J., Cornwall, H.L., Smith, E.S. (2016). Ear structures of the naked mole-rat, Heterocephalus glaber, and its relatives (Rodentia: Bathyergidae). PLOS ONE, 11, e0167079.

Mason, M.J., Lai, F.W.S., Li, J.-G., Nevo, E. (2010). Middle ear structure and bone conduction in Spalax, Eospalax and Tachyoryctes mole-rats (Rodentia: Spalacidae). Journal of Morphology, $271,462-472$.

Mason, M.J., Lucas, S.J., Wise, E.R., Stein, R.S., Duer, M.J. (2006). Ossicular density in golden moles (Chrysochloridae). Journal of Comparative Physiology A: Neuroethology, Sensory, Neural, and Behavioral Physiology, 192, 1349-1357.

Mason, M.J., Narins, P.M. (2001). Seismic signal use by fossorial mammals. American Zoologist, 41, 1171-1184.

Meester, J. (1974). Family Chrysochloridae. In: Meester J, Setzer HW, editors. The Mammals of Africa: an Identification Manual. Washington: Smithsonian Institution Press. pp. 1-7.

Mein, P., Pickford, M. (2003). Insectivora from Arrisdrift, a basal Middle Miocene locality in southern Namibia. Memoir of the Geological Survey of Namibia, 19, 143-146. 
Ogg, J.G., Ogg, G.M., Gradstein, F.M. (2016). A Concise Geologic Time Scale 2016. Amsterdam: Elsevier B.V.

Pickford, M. (2015a). Bothriogenys (Anthracotheriidae) from the Bartonian of Eoridge, Namibia. Communications of the Geological Survey of Namibia, 16, 215-222.

Pickford, M. (2015b). Cenozoic geology of the Northern Sperrgebiet, Namibia, accenting the Palaeogene. Communications of the Geological Survey of Namibia, 16, 10-104.

Pickford, M. (2015c). Chrysochloridae (Mammalia) from the Lutetian (Middle Eocene) of Black Crow, Namibia. Communications of the Geological Survey of Namibia, 16, 105-113.

Pickford, M. (2015d). Late Eocene Chrysochloridae (Mammalia) from the Sperrgebiet, Namibia. Communications of the Geological Survey of Namibia, 16, 153-193.

Pickford, M. (2015e). Late Eocene Potamogalidae and Tenrecidae (Mammalia) from the Sperrgebiet, Namibia. Communications of the Geological Survey of Namibia, 16, 114-152.

Pickford, M. (2015f). New Titanohyracidae (Hyracoidea: Afrotheria) from the Late Eocene of Namibia. Communications of the Geological Survey of Namibia, 16, 200-214.

Pickford, M., Sawada, Y., Hyodo, H., Senut, B. (2013). Radio-isotopic age control for Palaeogene deposits of the Northern Sperrgebiet, Namibia. Communications of the Geological Survey of Namibia, 15, 3-15.

Pickford, M., Senut, B., Mocke, H., Mourer-Chauviré, C., Rage, J.-C., Mein, P. (2014). Eocene aridity in southwestern Africa: timing of onset and biological consequences. Transactions of the Royal Society of South Africa, 69, 139144.

Pickford, M., Senut, B., Morales, J., Mein, P., Sanchez, I.M. (2008). Mammalia from the Lutetian of Namibia. Memoir of the Geological Survey of Namibia, 20, 465-514.

Pye, A. (1970). The aural anatomy of bats. Bijdragen tot de Dierkunde, 40, 67-70.

Pye, A. (1977). The structure of the cochlea in some myomorph and caviomorph rodents. Journal of Zoology, 182, 309-321. 
Sallam, H.M., Seiffert, E.R. (2016). New phiomorph rodents from the latest Eocene of Egypt, and the impact of Bayesian "clock"-based phylogenetic methods on estimates of basal hystricognath relationships and biochronology. PeerJ, 4, e1717; DOI 1710.7717/peerj.1717.

Schmitt, A., Gheerbrant, E. (2016). The ear region of earliest known elephant relatives: new light on the ancestral morphotype of proboscideans and afrotherians. Journal of Anatomy, 228, 137152.

Schwarz, E., Mertens, R. (1922). Ein neuer Chrysochloris aus Süd-Kamerun (Mamm. Ins.). Senckenbergiana, 4, 151-152.

Segall, W. (1973). Characteristics of the ear, especially the middle ear, in fossorial mammals, compared to those in the Manidae. Acta Anatomica, 86, 96-110.

Seiffert, E.R. (2007). A new estimate of afrotherian phylogeny based on simultaneous analysis of genomic, morphological, and fossil evidence. BMC Evolutionary Biology, 7, DOI:

10.1186/1471-2148-1187-1224.

Seiffert, E.R., Simons, E.L., Ryan, T.M., Bown, T.M., Attia, Y. (2007). New remains of Eocene and Oligocene Afrosoricida (Afrotheria) from Egypt, with implications for the origin(s) of afrosoricid zalambdodonty. Journal of Vertebrate Paleontology, 27, 963-972.

Simonetta, A.M. (1968). A new golden mole from Somalia with an appendix on the taxonomy of the family Chrysochloridae (Mammalia, Insectivora). Monitore Zoologico Italiano (NS), 2 (supplement), 27-55.

Skinner, J.D., Smithers, R.H.N. (1990). The Mammals of the Southern African Subregion. Pretoria: University of Pretoria.

Stanhope, M.J., Waddell, V.G., Madsen, O., de Jong, W.W., Hedges, S.B., Cleven, G.C., Kao, D., Springer, M.S. (1998). Molecular evidence for multiple origins of Insectivora and for a new order of endemic African insectivore mammals. Proceedings of the National Academy of Sciences of the USA, 95, 9967-9972. 
Stroganov, S.U. (1945). Morphological characters of the auditory ossicles of Recent Talpidae. Journal of Mammalogy, 26, 412-420.

von Mayer, A., O'Brien, G., Sarmiento, E.E. (1995). Functional and systematic implications of the ear in golden moles (Chrysochloridae). Journal of Zoology, 236, 417-430.

Willi, U.B., Bronner, G.N., Narins, P.M. (2006). Middle ear dynamics in response to seismic stimuli in the Cape golden mole (Chrysochloris asiatica). Journal of Experimental Biology, 209, 302313.

Wyss, A.R. (1987). The walrus auditory region and the monophyly of pinnipeds. American Museum Novitates, 2871, 1-31. 